\title{
Energy simulation and LCA for macro-scale analysis of eco-innovations in the housing stock
}

\author{
Karen Allacker ${ }^{1} \cdot$ Valentina Castellani $^{2} \cdot$ Giorgio Baldinelli $^{3} \cdot$ Francesco Bianchi $^{3} \cdot$ Catia Baldassarri $^{2} \cdot$ Serenella Sala $^{2} \mathbb{C}$
}

Received: 21 December 2017 / Accepted: 29 October 2018 / Published online: 14 December 2018

(C) The Author(s) 2018

\begin{abstract}
Purpose Energy consumption of buildings is one of the major drivers of environmental impacts. Life cycle assessment (LCA) may support the assessment of burdens and benefits associated to eco-innovations aiming at reducing these environmental impacts. Energy efficiency policies however typically focus on the meso- or macro-scale, while interventions are typically taken at the micro-scale. This paper presents an approach that bridges this gap by using the results of energy simulations and LCA studies at the building level to estimate the effect of micro-scale eco-innovations on the macro-scale, i.e. the housing stock in Europe.

Methods LCA and dynamic energy simulations are integrated to accurately assess the life cycle environmental burdens and benefits of eco-innovation measures at the building level. This allows quantitatively assessing the effectiveness of these measures to lower the energy use and environmental impact of buildings. The analysis at this micro-scale focuses on 24 representative residential buildings within the EU. For the upscaling to the EU housing stock, a hybrid approach is used. The results of the micro-scale analysis are upscaled to the EU housing stock scale by adopting the eco-innovation measures to (part of) the EU building stock (bottom-up approach) and extrapolating the relative impact reduction obtained for the reference buildings to the baseline stock model. The reference buildings in the baseline stock model have been developed by European Commission-Joint Research Centre based on a statistical analysis (top-down approach) of the European housing stock. The method is used to evaluate five scenarios covering various aspects: building components (building envelope insulation), technical installations (renewable energy), user behaviour (night setback of the setpoint temperature), and a combined scenario.

Results and discussion Results show that the proposed combination of bottom-up and top-down approaches allow accurately assessing the impact of eco-innovation measures at the macro-scale. The results indicate that a combination of policy measures is necessary to lower the environmental impacts of the building stock to a significative extent.

Conclusions Interventions addressing energy efficiency at building level may lead to the need of a trade-off between resource efficiency and environmental impacts. LCA integrated with dynamic energy simulation may help unveiling the potential improvements and burdens associated to eco-innovations.
\end{abstract}

Keywords Building stock · Eco-innovations · Energy simulation · Life cycle assessment · Policy support · Refurbishment · Scenarios

Responsible editor: Alexander Passer

Electronic supplementary material The online version of this article (https://doi.org/10.1007/s11367-018-1548-3) contains supplementary material, which is available to authorized users.

Serenella Sala

Serenella.sala@ec.europa.eu

1 KU Leuven, Faculty of Engineering Science, Department of Architecture, Kasteelpark Arenberg 1, 3001 Leuven, Belgium
2 European Commission Joint Research Centre, Directorate D Sustainable Resources - Bio-Economy Unit, Via Enrico Fermi 2749 TP290, 21027 Ispra, Italy

3 University of Perugia, Department of Engineering, Via Duranti 67, 06125 Perugia, Italy 


\section{Introduction}

The building sector causes important environmental impacts in terms of resource consumption, harmful emissions, and generation of waste. It is estimated that the construction and use of buildings in the European union (EU) account for about half of extracted materials and energy consumption and about a third of EU water consumption. The sector is also responsible for about one third of waste generated in Europe (EC 2014). The environmental pressures arise at different life cycle stages of a building, including the extraction of raw materials, the manufacturing of construction products, the building construction, use, renovation, and the management of building waste. Thanks to the Energy Performance of Buildings Directive (Directive 2010/31/EU, Directive 2012/27/EU), the operational energy use of buildings has been reduced to an important extent. In consequence, the embodied impact of buildings is becoming relatively more important (Seo et al. 2016; Vilches et al. 2017). This is widely recognized, and hence, recent studies increasingly focus on reducing the operational energy and the embodied impacts in parallel (Birgisdottir et al. 2017; Cabeza et al. 2013). In this context, the communication on resource efficiency opportunities in the building sector by the European Commission (EC 2014) highlights that the entire life cycle of a building must be considered in the selection of improvement options, to ensure that the environmental impacts are tackled effectively and to avoid burden shifting among life cycle stages. Life cycle assessment (LCA) is recognized as a valuable methodology to assess the environmental performance of eco-innovation options along the entire life cycle and to avoid burden shifting in time and among impact categories (Sala et al. 2013; Yu et al. 2016).

The application of LCA to the building stock is required to allow for evaluating the effectiveness of policy measures and unveiling possible trade-offs. This is considered particularly challenging because the assessment should be able to take into account the major sources of variability existing within the building stock (e.g. materials used, differences in energy demand due to climatic variations, differences in insulation level of the existing stock) as well as consumer's behaviour.

Baldassarri et al. (2017) and Lavagna et al. (2018) proposed an approach to identify the environmental hotspots of housing in Europe by defining representative buildings (archetypes) to model the European building stock in a reference year and run a life cycle impact assessment of the model (which represents a baseline scenario). Not surprisingly, the results indicate that the use phase is the most impacting life cycle stage for the majority of the impact categories (over $80 \%$ of impacts in 11 impact categories out of 15), due to the contribution of burning fossil fuels for heating and electricity production (Fig. S1 and Fig. S2, Electronic Supplementary Material-ESM). The production phase of construction materials follows in importance (from 3 to $53 \%$, depending on the impact category), mainly because of the production of steel, concrete, bricks and ceramic tiles.

Coherently with these results, sustainability policies and related actions in the building sector generally aim at improving energy and material efficiency of buildings. LCA can support the comparison of strategies to lower the energy and material use of buildings by considering all aspects of the interventions proposed, e.g. not limiting the evaluation to the energy performance, but including also the impact of construction materials used to insulate the building.

To allow for such a comprehensive and accurate assessment, life cycle inventories (LCIs) should incorporate, to the maximum possible extent, the knowledge coming from specific tools used in the building sector, such as building information models (BIM) and dynamic energy simulations. This can be more easily implemented when working at the level of the single building, for which specific data are available, and becomes more difficult when the scope of the assessment is larger, as it happens for the impact assessment of policies at the regional or country scale or even at the level of the entire Europe. This is reflected in a trade-off between the data granularity of the model, which is higher at the small scale and lower at the large scale, and the relevance of the results obtained in support to policy decisions, which is higher when the model is built at a larger scale (Fig. 1). In addition, policies aim at fostering benefits at the meso- or macro-scale (e.g. energy efficiency of the building stock, reduction of environmental impacts), while interventions are typically taken at the micro-scale.

Starting from Baldassarri et al. (2017), this paper discusses an approach that bridges this gap by using the results of dynamic energy simulations and LCA at the building level to calculate the effect of micro scale measures (i.e. at building level) on the macro-scale, i.e. the housing stock in Europe. The approach proposed is used to assess the effect of various measures in terms of life cycle impact reduction at the macroscale. Measures cover different levels, namely acting at the building component level (building envelope insulation), at the technical installations level (i.e. integration of renewable energy), and at the user behaviour level.

The objective of this paper is threefold. Firstly, it aims at defining an appropriate method for integrating dynamic energy simulations and LCA for assessing the environmental impact of different types of eco-innovation measures at the macro-scale (i.e. EU housing stock). Secondly, the purpose is to apply the approach developed to evaluate the environmental burdens and benefits associated to the implementation of eco-innovation scenarios, focusing on the reduction of operational energy use. Thirdly, the paper aims at unveiling the added value, challenges and limitations of the use of the method for its intended purpose.

The remaining of the paper is structured as follows. The subsequent sections of the introductory chapter provide an overview of currently used methods for macro-scale analyses of housing stocks and for linking micro-scale dynamic energy 
Fig. 1 Trade-off between data granularity and policy relevance
Data granularity

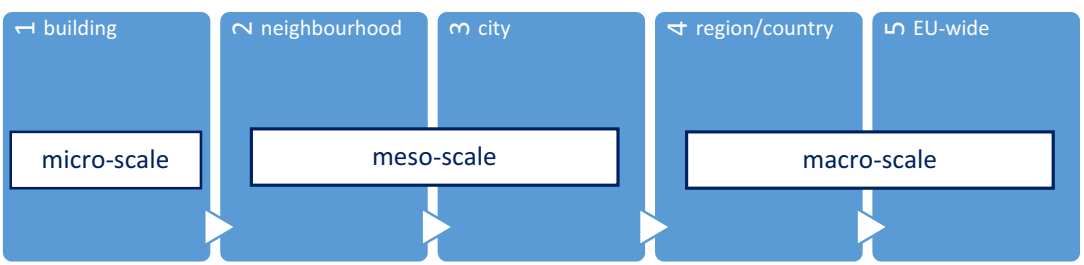

Policy-relevance simulations with LCA. The state of the art on current methods relevant for this research is followed by a chapter describing the methodology used in this study, a chapter on the research results and discussion, a chapter on the added value and challenges identified related to the method proposed and a final chapter summarizing the conclusions.

\subsection{Macro-scale analysis of housing stocks—state of the art}

The development of methodologies for macro-scale analyses is crucial to evaluate the environmental impacts of building stocks, the reduction potential, and eventually to support decision in sustainable planning and policy making at the macroscale. In 2015, Lotteau et al. published a review of studies at the neighbourhood scale and, more recently, in 2017, Mastrucci et al. made a thorough review of studies at larger building scales (from the urban to the transnational scale). Mastrucci et al. identified a common structure in the studies reviewed. They all consist of three methodological models: a building stock aggregation model, a building stock energy model, and an LCA model.

Firstly, building stock aggregation models are used to describe the entire building stock under investigation. According to the review of Mastrucci et al. (2017), two approaches are typically followed: the archetypes and building-by-building. The archetypes or typological approach consists of the definition of "reference buildings" according to a number of building features. In literature, the number of archetypes increases with the scale of the study (from micro to macro) as smaller regions - in general-present more uniform building types. Once the building types have been defined, each one is analysed and the global environmental impacts at the stock level are evaluated through upscaling factors. This approach has been largely used in the past to assess the energy performance of buildings (Mata et al. 2013; Theodoridou et al. 2011; Sartori et al. 2009; Caputo et al. 2013) for studies with national, regional or municipal scopes (Loga et al. 2016). This approach also reflects the content of the recommendation by the European Commission "Delegated Regulation No.244/2012"
(European Commission 2012a) and its accompanying Guidelines (European Commission 2012b). According to the regulation, European Member States are required to define reference buildings that should represent their typical and average building stock, in order to obtain general results consistent with the characteristics of the entire building stock. The building-by-building approach consists of modeling either each building of the stock, if the area is relatively small (e.g. district and municipality scale), or a sample of the buildings in case of larger areas (national level).

Two relevant aspects in the definition of the building stock are time and space related considerations. In the definition of the building stock, many studies include a spatial differentiation. There are different levels of accuracy in the spatialization, from the attribution of a specific archetype building to each defined location area to a more sophisticated use of geographical information systems (GIS) data and processing. Time-related aspects take into account the dynamics of the stock in terms of size, composition and renovation state. Broadly, existing dwelling stock models can be classified into two types: (i) static and (ii) dynamic. Static dwelling stock models focus on the stock at a precise moment in time (Nichols and Kockelman 2014; Saner et al. 2013). Dynamic models include the evolution in time of the building stock. The dynamic models are further divided into (a) input-driven or activity-driven and (b) stock-driven (Vásquez et al. 2016). The activity-driven models (Heeren et al. 2013; Onat et al. 2014; McKenna et al. 2013; Bettgenhäuser 2013; Boermans et al. 2012; Sartori et al. 2009) generally use construction and demolition rates, mostly based on historic trends, as drivers. The stock-driven models (Sandberg et al. 2011; Sandberg and Brattebø 2012; Pauliuk et al. 2013) use the service demand/ provision concept which relies on time-changing factors such as population and preference in size and type of building.

Secondly, energy models are needed in building stock assessments to determine the energy use of the building stock. There are two fundamental classes of modelling methods used to predict and analyse the overall building stock energy use performance: top-down and bottom-up approaches (Kavgic et al. 2010). The top-down modelling approach typically aims at 
fitting a historical time series of national energy consumption. It describes the energy consumption at an aggregated level using macro-economic or other statistics, and it is able to show the relationship between different economic variables and energy demand (e.g. unit consumption for space and water heating per dwelling, coal consumption of residential buildings for space heating). This method is not able to model new technologies which have no historical consumption data. Bottom-up methods encompass both engineering-based and statistical bottom-up approaches (Mastrucci et al. 2017). The engineering-based methods consist of simulations run on building models with the aim of estimating the heating and cooling demand. The calculation is based on the energy balance of the built environment and thermo-physical properties of the envelope elements. Two main approaches are possible: the simpler one hypothesizes steadystate conditions, resulting easier to use but less precise, and the more complex one, on the contrary, simulates the building behaviour in transient regime, with simulation time steps depending on the grade of accuracy desired (see Sect. 1.2). This is the most efficient way of evaluating new technologies. Statistical bottomup approaches are based on direct measurement of the energy consumption, and then statistical methods (e.g. linear regression model) are applied for scaling up to the entire stock.

Finally, the above described models (building stock aggregation, building stock energy model) need to be integrated in an LCA model of the building stock at large scale. Mastrucci et al. (2017) offer an overview of the state of the art of LCA of building stocks. As well as for the present study, the goal of the reviewed studies was to support policy making. Among the reviewed studies, one is about residential buildings in the European Union (EC-JRC 2008, Nemry et al 2010). In particular, it has the same final objective as the present study that is to compare the EU current situation with eco-innovative scenarios to show the potential for improving the environmental performance. There are important differences between the study of Nemry et al. (2010) and the present study. The major differences are summarized here, while a detailed description of the method of the present study is discussed in the chapter Method. In both studies, an engineering approach has been used for the energy analysis but in the study of Nemry et al. (2010), simulations have been run in steady-state conditions, whereas in the present study, dynamic simulations have been included. End use consumption other than heating demand has not been included by Nemry et al. (2010) while the present study includes the full operational energy use. The present study includes the construction phase, whereas Nemry et al. (2010) decided to omit it, as they argue that it was not relevant for the identification of improvement options. Nevertheless, they included the transportation of the construction materials as we did in the present study. Nemry et al. (2010) assumed a reference floor area as functional unit, whereas in the present study, the per-person functional unit has been adopted. Finally, for the environmental impact assessment, Nemry et al. (2010) used CML 2001 to evaluate ODP, AP, EP and POCP in addition to $\mathrm{CC}$, whereas in the present study, the calculation of the potential impacts on the environment follows ILCD (International Reference Life Cycle Data System) recommendations for life cycle impact assessment (LCIA) at midpoint (EC-JRC 2011), assessing impacts in 15 impact categories.

\subsection{Linking energy simulations and LCA at micro-scale (building level)—state of the art}

To make accurate calculations, taking into account the dynamic nature of the use phase of buildings', advanced simulation software tools areneeded. Several dynamic energy simulation tools exist such as Energyplus and TRNSYS. Research related to sustainable refurbishment of buildings often focuses on improving the energy performance of buildings and transforming existing buildings into nearly zero energy buildings (Asadi et al. 2012; Brown et al. 2013; Ma et al. 2012; Silva et al. 2013). These studies have a limited scope regarding sustainability as operational energy is the only focus. When the goal of the study is to define the most appropriate refurbishment strategies to reduce the life cycle impact of a building by diminishing its operational energy use, those dynamic energy simulations can be combined with LCA and used in a scenario-based comparative analysis. Several studies use such an approach (Famuyibo et al. 2013; Pombo et al. 2016; Thiers and Peuportier 2012). Another example of such studies is the work of Biswas et al. (2016) assessing four insulation materials applied in commercial buildings to evaluate direct and indirect environmental impacts. To ensure cost-efficiency, some researchers consider financial costs (investment and/or life cycle costs) whether or not combined with an LCA (Allacker and De Troyer 2012; Ostermeyer et al. 2013; Vrijders et al. 2012). Energy simulations have been applied to existing and new buildings according to ASHRAE 90.1 (2016). Bortolin et al. (2015), for example, made an LCA and energy simulation study of an Italian historical building damaged by an earthquake. Various insulation materials were assessed from a life cycle environmental perspective, using the results of the energy simulations for the estimation of the operational energy use before and after reconstruction. Stazi et al. (2017) used a different approach as they compared numerical simulations for the assessment of the comfort level, environmental impacts and costs with monitoring data of real residential buildings in the Mediterranean climate. The LCA results underline that notwithstanding the additional thermal insulation reduces winter season energy consumption, a large thickness of the insulation material determines significant environmental impacts, leading to the need of identifying a trade-off between energy savings and environmental aspects. Another example of scenario-based analysis, combining building energy simulation and LCA, is related to the use of a BIM-enhanced LCA method to determine the effect of material specifications on the life cycle environmental impact of a primary school (Ajayi et al. 
2015). Several scenarios were analysed by varying the material specifications in terms of whole building materials. Roux et al. (2016) performed a more advanced step regarding the integration of energy simulations in LCA as they considered both the climate change and the evolution of the energy mix, using simulation methods that take into account meteorological data. The main finding of the paper showed that, even if the studied building had a high energy performance (Passivhaus standardhttp://passivehouse.com), operational energy use was still an important contributor to the life cycle environmental impact, i.e. more than $50 \%$ for the consequential LCA approach and around $40 \%$ for the scenarios calculated with an attributional LCA approach. Peuportier et al. (2013) overcome the usual attention of LCA for the building energy efficiency by integrating the influence of the inhabitants' behaviour. Dynamic energy simulations become essential in order to consider the variability in occupancy scenarios, given the influence of occupant behaviour in the energy performance of buildings revealed very strong. An overall economic and environmental analysis of energy renovation packages for European office buildings has been conducted by Gustafsson et al. (2017). Five-floor office buildings have been modelled in the TRNSYS environment including the modelling of the thermal plant, ventilation, infiltrations and internal gains, such as occupants' behaviour and the use of computers, monitors and other electronic equipment. Scenarios of functional renovations were applied to the building offices, to compare several solutions in terms of energy plants and envelope insulation. Various studies moreover used energy simulations in the context of design optimisation. Inyim and Zhu (2013) for example extend the environmental and energy assessment with a design phase based on multiple objectives, considering energy aspects and realworld uncertainties. A computer algorithm aids in the process of finding optimal or near optimal solutions of combined building designs. Azari et al. (2016) use a multi-objective optimization algorithm for finding the optimum building envelope design, considering the energy use and life cycle environmental impact of a low-rise office building in Seattle, Washington. The scenarios focused on several design points: insulation material, window type, window frame material, wall thermal resistance and south and north window-to-wall ratios. Beyond the energy simulation in combination with LCA, a hybrid artificial neural network and a genetic algorithm approach were used as the optimization technique. Cellura et al. (2017) concentrated on the integration and validation of building simulation and LCA through the programming of a TRNSYS component. Their work was tailored for calculating the total energy requirement and global warming potential, but it was characterized by a strong flexibility and it could perform complex integrated analyses. In this latter work, a large number of papers regarding the integrated tools are listed (Pedersen et al. 2008; Petersen 1999; Wong and Zhou 2015; Jrade and Jalaei 2012; Rodrigues and Freire 2014; Lolli et al. 2017).

\section{Methods}

Several methodological steps were taken to reach the goal of the present study. Before elaborating the building stock model, the energy model, and the LCA model, the selected ecoinnovation measures are described in order to allow a clear focus of the paper.

\subsection{Selection of the scenarios}

As highlighted in the introduction, the environmental impacst of the housing stock are caused by several main drivers. This paper focuses on reducing the operational energy use in buildings, which is identified as an important driver of environmental hotspot of the European housing stock (Baldassarri et al. 2017). The measures to be tested have been selected based on the analysis of several policy priorities (i.e. improving energy efficiency, extending the production of energy from renewable resources, moving towards bio-economy) combined with the findings of energy simulations of a broader set of interventions (i.e. analysing the efficiency of potential measures-see Table S1, Electronic Supplementary Material-ESM). The scenarios have been selected based on their relevance, efficiency and type of intervention. They are illustrative and not exhaustive in terms of required interventions for reducing the environmental impact of the housing stock in Europe.

The scenarios cover three types of interventions: (1) increasing the insulation level of the building envelope (i.e. outer walls), (2) improving technical systems (i.e. integrating solar thermal system), and (3) acting on behavioural changes of the building users (consumers) (i.e. night setback setpoint temperature). The selected interventions range from building component level, to introducing renewable energy up to changing occupants' behaviour.

\subsection{Modelling approach}

Building stock model The static model of Baldassarri et al. (2017), which is the starting point of the present study, uses the archetype approach. More specifically, 24 reference buildings (for Europe) have been defined combining three climatic zones (cold, moderate, and warm, illustrated in Table S2-ESM) - to cover space-related aspects - two building types (representing single family and multi-family housing) and four construction periods (before 1945, 1945-1969, 19701989, and 1990-2010) - to cover time related constraints. They are representative of the residential EU built environment. The reference year of the model is 2010 .

The main data sources for the definition of the archetypes were the projects: i) Typology Approach for Building Stock Energy Assessment (TABULA) (2009-2012), ii) Energy Performance Indicator Tracking Schemesfor the Continuous Optimisation of Refurbishment Processesin European 
Housing Stocks (EPISCOPE) (2013-2016), iii) Policies to ENforce the TRAnsition to Nearly Zero Energy buildings in the EU-27 (ENTRANZE 2014), and iv) Monitoring of EU and national energy efficiency targets (ODYSSEE 2016) funded by the European programme Intelligent Energy Europe (IEE). The results of the projects were collected together with relevant information of the European building stock in the Buildings Performance Institute Europe (BPIE)'s Data Hub (2017). The same sources were used to model the inventory of the 24 reference buildings (e.g. construction materials and operational energy use). A detailed description of the building archetypes for each climatic context can be found in Baldassarri et al. (2017) and in Lavagna et al. (2018). The subsequent paragraphs summarize the main modelling characteristics.

The technical solutions of the envelope (walls, windows, roofs, etc.) of the representative buildings have been modelled (size and choice of materials), taking into account the typical thermal transmittance ( $U$ value) of the specific construction period and combining data from TABULA (Ballarini et al. 2014), the BPIE (2017), and expert judgements on the characteristics of the regional construction materials. The data sources used to define the characteristics of the envelope are different for the three climate zones considered. For the moderate and warm areas, the main source was the TABULA project which defined representative buildings for each of the countries involved in the project, further grouped to define a representative building for each of the two climate areas. For the cold area, the main source used was a study by Meijer and Itard (2008), complemented by interviews to local architects as explained in Lavagna et al. (2016). Based on these studies, a massive building envelope system is assumed to be representative for all EU dwellings in the warm and moderate climates. For cold climates, a massive building envelope system is assumed for the multi-family houses (MFH), whereas a lightweight construction system is assumed for the single family houses (SFH). Stone wool is chosen as insulation as it (together with glass wool) accounts for $60 \%$ of the market of insulating materials in Europe; organic foamy materials, expanded and extruded polystyrene and polyurethane, account for only 27\% of the market (Papadopoulos 2005).

The upscaling of the life cycle inventories of the representative dwellings to represent the European building stock is done based on the number of buildings (in Europe) per type (Table S3-ESM). For the statistical analysis, the reference year 2010 was used (i.e. number of dwellings, population, energy consumption). For this upscaling, various data sources had to be combined because no reports covered all information needed. For instance, the total number of permanently occupied dwellings was retrieved from ODYSSEE, because this source provides the information per country. The data were validated by comparing the total number of dwellings in the EU (calculated as the sum of the dwellings per member state) with the same information provided by another source, namely the BPIE. It was found that there was a good correspondence (difference lower than $0.01 \%$ ) between the two sources on the number of dwellings and the total dwelling area (as reported in Lavagna et al. 2016). The analysis of the available statistical data moreover revealed that the way of aggregating differs from country to country. This can partly be explained by the differences in national building classification rules. Moreover, data for the reference year 2010 was not always available for all Member States of the EU. Data related to whole Europe and the year 2008 have been used where there were no data available for EU in 2010. As the average values of statistical data (e.g. square meters of a dwelling) fluctuate very little from year to year and among countries, this was seen as an acceptable approach to fill the data gaps. The main source of data for the year of construction of the buildings was ENTRANZE. Those data were validated by comparing these with the study "Housing statistics in the European Union 2010" (Dol and Haffner 2010), data used in the IMPRO-building study (ECJRC 2008) and ODYSSEE. Also in this case, discrepancies were identified among the sources at the level of single countries, but there was a good correspondence for data at the European scale (details can be found in Lavagna et al. 2016).

Notwithstanding the limitations due to the choice of using a limited number of archetypes, and the need to use various (and sometimes not fully converging) data sources for the modelling of the building stock, it is important to highlight that the use of data from European projects and databases, validated through comparisons and cross-checks, ensures an overall representativeness of the EU building stock. In fact, the cross-comparison of data from various sources highlighted that the variability among sources was at the country level rather than at the EU level.

Energy model For the energy model of the baseline scenario in the study of Baldassarri et al. (2017), a top-down approach was used. The energy consumption of each archetype was defined based on countries statistical data combined with individual countries energy carrier mixes. The countries were grouped per climatic zone defined in the baseline model (i.e. warm, moderate, cold), and an average value was allocated to the archetypes. In particular, the average heating consumption for each model was calculated by multiplying the average heating consumption per square meter (calculated starting from average values per each country included in the climate zone considered) by the average floor area for each model. For the other types of energy consumption, i.e. water heating, space cooling, lighting, cooking and appliances, a European average value per person for each energy consumption type was considered and then multiplied by the number of people per dwelling.

The novelty of the present study lies in upscaling LCA results of interventions at micro-scale level (building) to investigate their life cycle impact on the EU building stock level. The method consists of upscaling bottom-up life cycle assessments of materials (see subsequent paragraphs on LCA model) with a hybrid energy model for estimating the impact reduction due to 
the decrease in operational energy use. To estimate the latter, dynamic energy simulations have been run for each archetype model in the baseline scenario and after applying the ecoinnovation measures (micro-scale). Based on these simulations, the percentage reduction in energy consumption was determined per square meter of floor area. This percentage reduction has then been applied to the baseline energy consumption of each archetype defined with the top-down approach as described before. This results in absolute energy savings at the macro-scale level by using the upscaling method mentioned for the building stock model. This hybrid method is used to increase robustness of the methodology and reliability of the results taking advantages from the strong points of the two modelling approaches. The hybrid approach used for the estimation of the decrease in environmental impact due to operational energy reduction is schematically presented in Fig. 2.

The dynamic energy simulations are implemented with the software TRNSYS. In a first step, the baseline scenario is modelled in TRNSYS in order to calculate the energy use for the baseline scenario. This is necessary in order to accurately estimate the energy reduction due to the eco-innovation measure in the next step. The baseline scenario is modelled according to the year of construction and the typical structure related to the specific period. However, due to limitation in data availability, the underpinning parameters for building built before 1970 were the same. Moreover, the thermo-physical properties of the opaque and transparent envelope are defined for the different climate zones. For the sake of brevity, the authors do not report the properties of each layer and glass but refer to Lavagna et al. (2016) who collect the results of the projects TABULA (20092012), EPISCOPE (2013-2016) and ENTRANZE for a detailed description of the building models. Lavagna et al. (2018) defined the typical archetypes for single and multi-family buildings, according to the construction period and the climate zones.

Secondly, the energy use for each single eco-innovation scenario is simulated. Based on the difference between the results, the energy savings are calculated, expressed as percentage. This percentage reduction is then used to calculate the remaining operational energy use when the eco-innovation measure is taken, departing from national statistical data for the various dwelling types.

Three climate datasets are selected, representing the three climatic zones included in the LCA model of the housing stock. More specifically, the following climate data are used: Athens to represent the warm climate, Strasbourg to represent the moderate climate and Helsinki to represent the cold climate. This is in line with other energy-related studies on ecoinnovation, such as the Ecodesign Preparatory Study on Windows (ENER Lot 32) (www.ecodesign-windows.eu).

LCA model Baldassarri et al. (2017) describe in detail all the assumptions to build the LCA model. A brief summary of the main steps follows. Once the archetypes were defined, the corresponding process-based LCI models were developed for each stage of the life cycle of the buildings. The system boundaries were defined according to the European Standards EN 15978:2011 and EN 15804:2012, from the production stage to the end-of-life stage. The inventories were organized according to the modular structure of the EN 15978: production stage, construction stage (transport, energy and waste), use stage (energy, water), use stage (maintenance/replacement) and end-of-life stage. Ecoinvent 3.2 was used as the main source of secondary data. The datasets from the Ecoinvent system model "allocation, default" were used. No cut-off was considered. The total service life of the buildings was assumed to be 100 years (considering that a relevant share of the building stock had been constructed before 1945, i.e. more than 70 years ago). A per-person (average EU citizen) per-year functional unit has been defined.

Each of the 24 reference buildings was modelled in a similar way, differentiating materials and energy consumption on the basis of typological features. An LCA was performed for each archetype dwelling, for the baseline scenario and for four ecoinnovation scenarios, entailing: three distinct measures and a combined eco-innovation one. The LCA model of the ecoinnovation scenarios was structured in a way that the impacts related to the eco-innovation measure could be distinguished easily (Table 1) from the impacts of the materials included in the baseline scenario and this for each life cycle stage. The implementation of the eco-innovation measures typically leads to a reduction in the operational energy use (i.e. savings due to the eco-innovation), and hence, the use phase of the eco-innovation scenarios differs from the one of the baseline scenario (Table 1).

The materials related to the intervention were modelled at the micro-scale level (i.e. for each single building separately). The material amounts were then upscaled by multiplying the amounts per dwelling by the number of dwellings in the three climatic zones. The calculation of the reduction in operational energy has been explained in the previous section, focusing on the energy model. To express the impacts per functional unit, the obtained results are divided by the number of persons in each climatic zone.

\subsection{Scenario modelling}

Four scenarios have been modelled, namely related to (I) improved insulation, (II) production of hot water with solar thermal panels, (III) night setback of setpoint temperature in the "heating, ventilation and air conditioning" (HVAC) systems, and (IV) a combination of the scenarios I, II and III.

\subsubsection{Scenario I: insulation of outer walls}

The first scenario focuses on improving the building skin thermal resistance by adding insulation in the outer walls. Table 2 summarizes the modelling assumptions for this scenario and the related operational energy use for heating calculated via dynamic energy simulations combined with statistical data, as explained in 
Fig. 2 Schematic representation of the hybrid approach to calculate the reduced energy use at macro-scale due to ecoinnovation measures taken at micro-scale

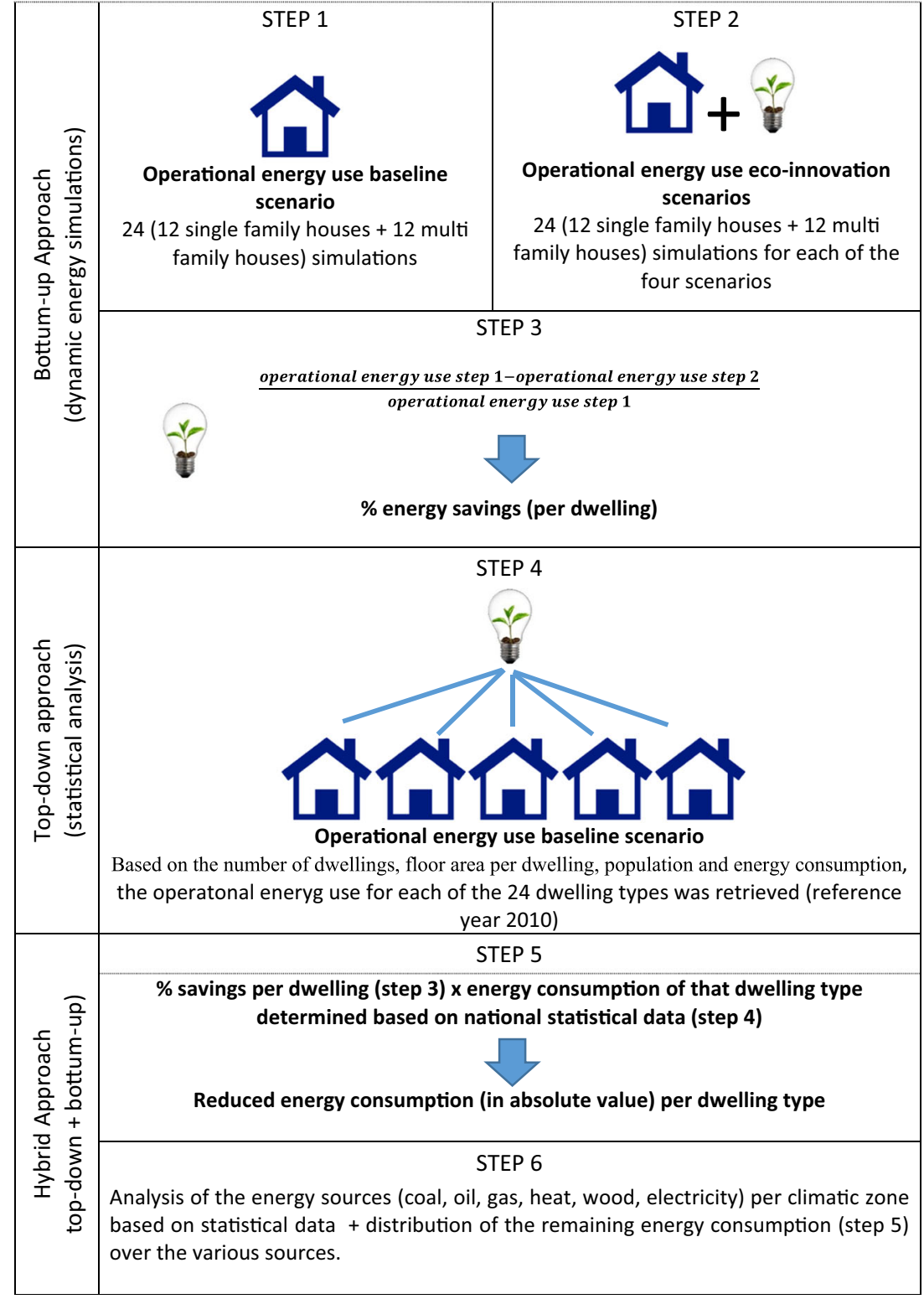

Table 1 Modelling structure of the scenarios to improve the EU housing stock

\begin{tabular}{lcc}
\hline Life cycle stage & Baseline scenario & Eco-innovation scenario \\
\hline $\begin{array}{l}\text { Production of materials (baseline scenario) } \\
\text { Production of additional materials needed for the eco-innovation measure }\end{array}$ & $\mathrm{x}$ & $\mathrm{x}$ \\
$\begin{array}{l}\text { Construction stage (baseline scenario) } \\
\text { Construction stage: additional processes/products required for the eco-innovation measure }\end{array}$ & $\mathrm{x}$ & $\mathrm{x}$ \\
Use phase: energy and water consumption (baseline scenario) & $\mathrm{x}$ & $\mathrm{x}$ \\
Use phase: energy and water consumption when eco-innovation measure is taken & & $\mathrm{x}$ \\
Use phase-maintenance of the building and its components (baseline scenario) & $\mathrm{x}$ \\
Use phase-maintenance of the additional components & $\mathrm{x}$ \\
End of life (baseline scenario) & & $\mathrm{x}$ \\
End of life of additional materials & & $\mathrm{x}$
\end{tabular}




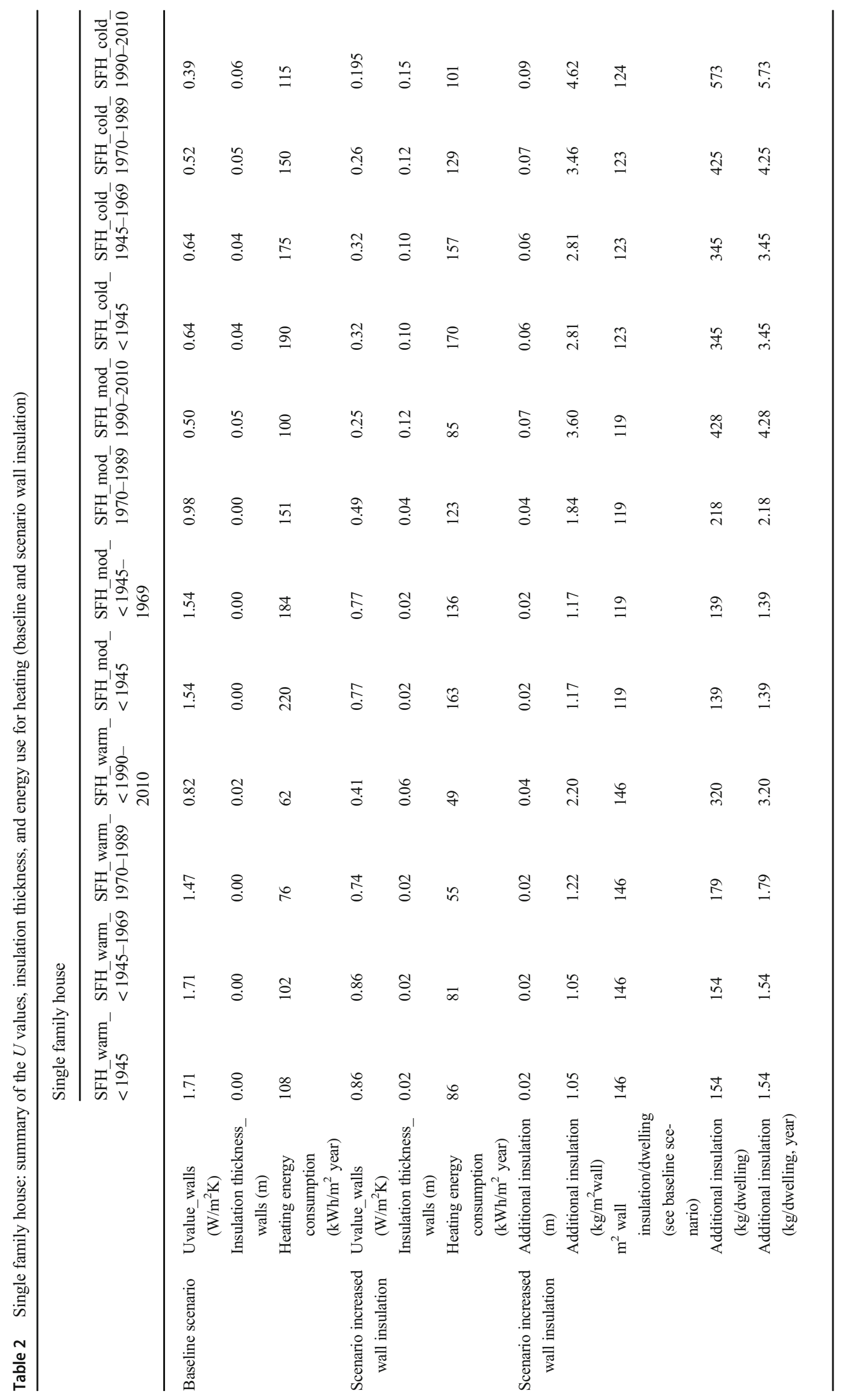


the previous section. The upper part in Table 2 is directly retrieved from the baseline model and is hence based on a statistical analysis (top-down approach). The average heating consumption for space heating $\left(\mathrm{kWh} / \mathrm{m}^{2}\right)$, for each dwelling type in each climatic zone, has been derived combining data from the BPIE Data Hub (BPIE 2017) and from two Intelligent Energy Europe projects (ODYSSEE and ENTRANZE). The second block in the table summarizes the modelling input for the scenario and is based on the assumption that the $U$ values of the existing walls are improved to such an extent that the $U$ values are halved. This insulation level obtained after the intervention is by no means meant as reflecting the optimal insulation level in renovation cases (determining the optimal insulation level was not part of the research goal). The scenario of reducing the thermal transmittance to half of its value is rather a pragmatic choice as it overcomes the problem linked to the absence of common levels of insulation requirements throughout the EU Member States and should be seen as representing the potential benefit of increasing the façade insulation.

The $U$ values are then used to calculate the insulation thickness (assuming a lambda value of $0.036 \mathrm{~W} /(\mathrm{mK})$, i.e. retrieved from Rockwool) and amount of insulation materials (assuming a density of $50 \mathrm{~kg} / \mathrm{m}^{3}$, i.e. same value as in the baseline scenario). As explained before, the benefits (in terms of reduced energy use) of the additional insulation are calculated via dynamic energy simulations (bottom-up approach). The results of these micro-scale simulations are summarized in Table 3. The percentage savings are used to calculate the heating energy consumption of this scenario, departing from the baseline scenario (i.e. third line of the scenario "increased wall insulation" in Table 2). For example, energy for space heating for a single family house in a warm climate built before 1945 equals $108 \mathrm{kWh} / \mathrm{m}^{2}$ per year (determined based on statistical analysis). According to the dynamic energy simulations, a reduction of $21 \%$ is achieved when increasing the wall insulation. This means the energy consumption for heating of the house equals $108-21 \% \times 108$ or $86 \mathrm{kWh} /$ $\mathrm{m}^{2}$. The heating consumption for space heating after the insulation is reported in the third line of the second block of Table 2. Tables similar to the single family house can be found in the supplementary information for the multi-family houses (Tables S4 and S5-ESM). The $U$ value halving is more effective in warm zones (in relative terms), where the starting level of wall insulation is quite poor, in respect to the moderate and cold zones, which are already well insulated in the baseline scenario. As a consequence, the wall insulation improvement in the hotter zones plays a more significant role respect to the other sources of heat dispersion, leading to higher percentage savings.

For the production stage, the additional insulation material as presented in Table 2 was modeled in the life cycle stage "Production of additional materials needed for the ecoinnovation measure".

The construction stage is modelled similarly as in the baseline scenario, i.e. assuming $4 \%$ of the materials become

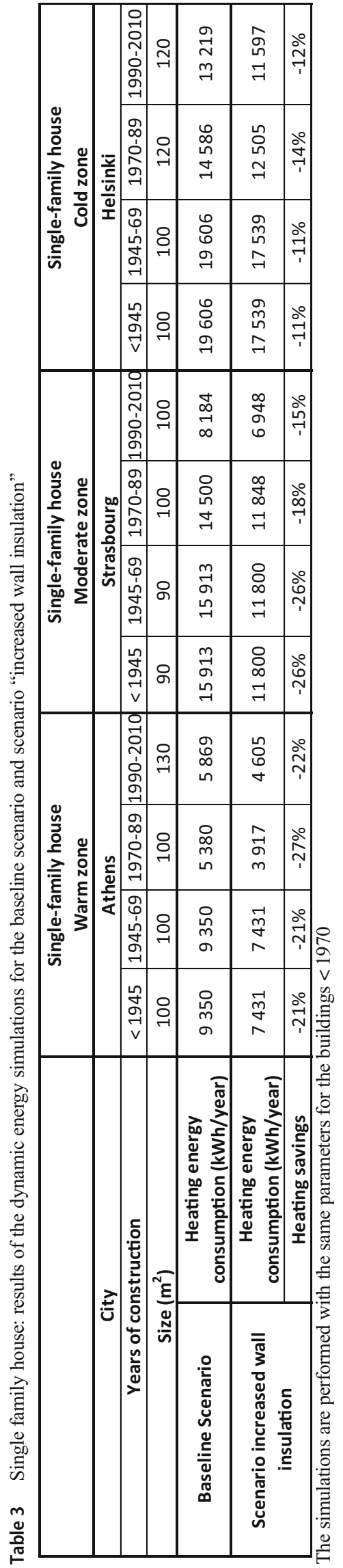


Table 4 Size of solar collector $\left(\mathrm{m}^{2}\right) /$ dwelling

\begin{tabular}{|c|c|c|c|c|c|c|c|c|}
\hline & \multicolumn{8}{|c|}{ Solar collector $\left(\mathrm{m}^{2}\right) /$ dwelling } \\
\hline & \multicolumn{4}{|c|}{ Single family house } & \multicolumn{4}{|c|}{ Multi-family house } \\
\hline & $<1945$ & $\begin{array}{l}1945- \\
1969\end{array}$ & $\begin{array}{l}1970- \\
1989\end{array}$ & $\begin{array}{l}1990- \\
2008\end{array}$ & $<1945$ & $\begin{array}{l}1945- \\
1969\end{array}$ & $\begin{array}{l}1970- \\
1989\end{array}$ & $\begin{array}{l}1990- \\
2008\end{array}$ \\
\hline Warm zone & 4.12 & 4.12 & 4.12 & 4.12 & 2.44 & 2.44 & 2.44 & 2.44 \\
\hline $\begin{array}{c}\text { Moderate } \\
\text { zone }\end{array}$ & 3.25 & 3.25 & 3.25 & 3.25 & 2.46 & 2.46 & 2.46 & 2.46 \\
\hline Cold zone & 3.39 & 3.39 & 3.39 & 3.39 & 2.01 & 2.01 & 2.01 & 2.01 \\
\hline
\end{tabular}

"construction waste" (as suggested in literature, e.g. Scheuer et al. 2003; Beccali et al. 2013; Asdrubali et al. 2013) and assuming the same transport scenario, i.e. transport over a distance of $50 \mathrm{~km}$ with a lorry of 3.5-7.5 t. No additional energy use is assumed for the installation of the additional components.

For the use phase-maintenance, it is assumed that the additional insulation is replaced twice during the life span of the building, i.e. after 30 and 60 years. No further maintenance activities are considered.

For the use phase-energy and water, the above-mentioned yearly energy use for heating (Table 5) has been distributed over the various energy sources assuming the same percentage distribution as in the baseline scenario (i.e. based on statistical data for the three climatic zones). For each of the energy sources, the same LCI datasets have been assumed as in the Basket of Products (BoP) housing baseline scenario. The water use in this scenario is identical as for the baseline scenario.

The end-of-life stage includes the dismantling process, transport to sorting plants, final disposal of waste materials and benefits from materials recycling and energy recovery (incineration). The same scenarios are assumed as for the insulation products in the baseline scenario.

\subsubsection{Scenario II: thermal solar system for production of domestic hot water}

The second scenario focuses on the installation of a thermal solar system for the production of domestic hot water, resulting in a reduced need of additional water heating. For this scenario, a collector surface of $1.2 \mathrm{~m}^{2} /$ person is assumed for both the single family and multi-family houses. For the single-family houses, a storage tank of 2501 is assumed in the warm climate and 2001 in the moderate and cold climate. For the multi-family houses, it is assumed that one large storage tank (2500 1 in the warm climate, 14001 in the moderate and 10001 in the cold climate) is installed for the whole building. The aforementioned tank volume derives from an optimization process in TRNSYS, as the ideal tank size depends on the geographical location, the domestic hot water (DHW) requirements and the surface of the collectors. The main objective of the optimization process is to find the highest energy saving in the DHW production, using the solar panels. The energy demand of hot water for each class of buildings and climate has been calculated. For each climate zone, DHW demand and collector surface, a TRNSYS model has been implemented including the solar tank with an auxiliary heating system. The results obtained through the simulation give the fraction of energy coming from the solar panel and the fraction of energy deriving from the auxiliary heating system. The energy saving is represented by the fraction of energy obtained from the solar panel, which is a parabolic concave-downward function of the volume tank. These assumptions lead to the sizing parameters as summarized in Tables 4 and 5. It is furthermore assumed that the inhabitants consume 601 of hot water per day per person with the following characteristics:

- $T_{\text {in }}$ (warm climate $)=15^{\circ} \mathrm{C}$

- $T_{\text {in }}$ (moderate climate $)=10^{\circ} \mathrm{C}$

- $T_{\text {in }}$ (cold climate $)=5^{\circ} \mathrm{C}$

- $T_{\text {user }}=45^{\circ} \mathrm{C}$
Table 5 Size of water storage tank (litres)/dwelling

\begin{tabular}{|c|c|c|c|c|c|c|c|c|}
\hline & \multicolumn{8}{|c|}{ Water storage tank (litres)/dwelling } \\
\hline & \multicolumn{4}{|c|}{ Single family house } & \multicolumn{4}{|c|}{ Multi-family house (16 apartment units) } \\
\hline & $<1945$ & $\begin{array}{l}1945- \\
1969\end{array}$ & $\begin{array}{l}1970- \\
1989\end{array}$ & $\begin{array}{l}1990- \\
2008\end{array}$ & $<1945$ & $\begin{array}{l}1945- \\
1969\end{array}$ & $\begin{array}{l}1970- \\
1989\end{array}$ & $\begin{array}{l}1990 \\
2008\end{array}$ \\
\hline Warm zone & \multicolumn{4}{|l|}{250} & \multicolumn{4}{|c|}{$=2500 / 16$} \\
\hline $\begin{array}{l}\text { Moderate } \\
\text { zone }\end{array}$ & \multicolumn{4}{|l|}{200} & \multicolumn{4}{|c|}{$=1400 / 16$} \\
\hline Cold zone & \multicolumn{4}{|l|}{200} & \multicolumn{4}{|c|}{$=1000 / 16$} \\
\hline
\end{tabular}


Table 6 Annual energy production by solar collector system (kWh/dwelling/year), based on dynamic energy simulations

\begin{tabular}{|c|c|c|c|c|c|c|c|c|}
\hline & \multicolumn{8}{|c|}{ Annual energy production solar collector $((\mathrm{kWh}) /$ dwelling $)$} \\
\hline & \multicolumn{4}{|c|}{ Single family house } & \multicolumn{4}{|c|}{ Multi-family house } \\
\hline & $<1945$ & $\begin{array}{l}1945- \\
1969\end{array}$ & $\begin{array}{l}1970- \\
1989\end{array}$ & $\begin{array}{l}1990- \\
2008\end{array}$ & $<1945$ & $\begin{array}{l}1945- \\
1969\end{array}$ & $\begin{array}{l}1970- \\
1989\end{array}$ & $\begin{array}{l}1990- \\
2008\end{array}$ \\
\hline Warm zone & 1554 & 1554 & 1554 & 1554 & 560 & 860 & 860 & 860 \\
\hline $\begin{array}{l}\text { Moderate } \\
\text { zone }\end{array}$ & 439 & 439 & 439 & 439 & 397 & 397 & 397 & 397 \\
\hline Cold zone & 453 & 453 & 453 & 453 & 314 & 314 & 314 & 314 \\
\hline
\end{tabular}

For the production stage, the additional materials and components necessary for the solar boiler system, i.e. collectors, pump, control system and storage tank, are modelled in the life cycle stage "Production of additional materials needed for the ecoinnovation measure". The appropriate Ecoinvent datasets are used as a base and are modified according to the sizing of the components as mentioned before. For the single family houses, the Ecoinvent dataset "Solar system, flat plate collector, onefamily house, hot water/CH/I U" is used as a base, while for the multi-family houses, the dataset "Solar system, flat plate collector, multiple dwelling, hot water/CH/I U" is used. The transport of the system to the construction site is removed from these datasets and modelled separately in the construction stage. The same is valid for the end-of-life processes, which are removed from the original dataset and added to the end-of-life stage.

The construction stage is modelled similarly as in the baseline scenario, i.e. assuming that $4 \%$ of the materials become construction waste and no additional energy use is assumed for the installation of the thermal solar system. For the transport to the construction site, a distance of $50 \mathrm{~km}$ is assumed with a van of less than $3.5 \mathrm{t}$ (Ecoinvent dataset: Transport, van $<3.5 \mathrm{t} / \mathrm{RER} \mathrm{U})$. In line with the assumptions of the Ecoinvent dataset of the solar collector, a weight of $440 \mathrm{~kg}$ is assumed.

The reduced heating demand for the production of hot water is considered in the use phase-energy and water. The production by the solar boiler system is calculated with dynamic energy simulations (see results in Table 6). These outcomes are then deducted from the energy use in the baseline scenario to calculate the remaining annual energy demand for the production of domestic hot water by the conventional system
(Table 7). Similarly, as for the scenario on increased wall insulation, the distribution of this energy use over the various energy sources is in line with the baseline scenario.

For the use phase-maintenance, it is assumed that $50 \%$ of the boiler system is replaced every 25 years (in line with the other technical systems in the baseline scenario). Within a building service life of 100 years, it means that the solar system is replaced once. This should be interpreted as an average replacement rate of boilers in the whole building stock and does not necessarily mean that for each building the boiler system is only replaced after 50 years. The LCI model takes into account the production, transport to construction phase and transport to EoL and EoL processes of the replaced thermal boiler system. No other maintenance activities are considered.

The end-of-life stage includes the dismantling process, transport to sorting plants, final disposal of waste materials, and benefits from materials recycling and energy recovery (incineration). The detailed assumptions on the end-of-life of the thermal solar system are summarized in supplementary information (Table S6-ESM).

\subsubsection{Scenario III: night setback of setpoint temperature in HVAC systems}

The third scenario focuses on reducing the room temperature at night, referred to as night setback of setpoint temperature for heating. This scenario is included as an example of potential behavioural change of the users. In this scenario, it is investigated if people lower the indoor setpoint temperature of their
Table 7 Remaining annual energy demand for domestic hot water to be covered by the conventional system $(\mathrm{kWh} /$ dwelling/year)

\begin{tabular}{|c|c|c|c|c|c|c|c|c|}
\hline & \multicolumn{8}{|c|}{ Annual remaining energy demand to be covered by the conventional system $((\mathrm{kWh}) / \mathrm{dwelling})$} \\
\hline & \multicolumn{4}{|c|}{ Single family house } & \multicolumn{4}{|c|}{ Multi-family house } \\
\hline & $<1945$ & $\begin{array}{l}1945- \\
1969\end{array}$ & $\begin{array}{l}1970- \\
1989\end{array}$ & $\begin{array}{l}1990- \\
2008\end{array}$ & $<1945$ & $\begin{array}{l}1945- \\
1969\end{array}$ & $\begin{array}{l}1970- \\
1989\end{array}$ & $\begin{array}{l}1990- \\
2008\end{array}$ \\
\hline Warm zone & 516 & 516 & 516 & 516 & 365 & 365 & 365 & 365 \\
\hline $\begin{array}{l}\text { Moderate } \\
\text { zone }\end{array}$ & 2403 & 2403 & 2403 & 2403 & 1747 & 1747 & 1747 & 1747 \\
\hline Cold zone & 2850 & 2850 & 2850 & 2850 & 1642 & 1642 & 1642 & 1642 \\
\hline
\end{tabular}


Table 8 Single family houses: reduction in heating demand due to night setback setpoint temperature based on dynamic energy calculations

\begin{tabular}{|c|c|c|c|c|c|c|c|c|c|c|}
\hline & & \multicolumn{3}{|c|}{$\begin{array}{c}\text { Single-family house } \\
\text { Warm zone }\end{array}$} & \multicolumn{3}{|c|}{$\begin{array}{c}\text { Single-family house } \\
\text { Moderate zone }\end{array}$} & \multicolumn{3}{|c|}{$\begin{array}{c}\text { Single-family house } \\
\text { Cold zone }\end{array}$} \\
\hline \multicolumn{2}{|l|}{ City } & \multicolumn{3}{|c|}{ Athens } & \multicolumn{3}{|c|}{ Strasbourg } & \multicolumn{3}{|c|}{ Helsinki } \\
\hline \multicolumn{2}{|l|}{ Year of construction } & $<1970$ & 1970-1989 & 1990-2010 & $<1970$ & 1970-1989 & $1990-2010$ & $<1970$ & 1970-1989 & 1990-2010 \\
\hline \multicolumn{2}{|l|}{ Size $\left(\mathrm{m}^{2}\right)$} & 100 & 100 & 130 & 90 & 100 & 100 & 100 & 120 & 120 \\
\hline Baseline scenario & \multirow{2}{*}{$\begin{array}{l}\text { Heating energy } \\
\text { consumption (kWh/year) }\end{array}$} & 9350 & 5380 & 5869 & 15913 & 14500 & 8184 & 19606 & 14586 & 13219 \\
\hline \multirow{2}{*}{ Scenario night setback temperature } & & 5992 & 3261 & 3772 & 12772 & 11486 & 6470 & 16759 & 12505 & 11322 \\
\hline & Heating savings & $-36 \%$ & $-39 \%$ & $-36 \%$ & $-20 \%$ & $-21 \%$ & $-21 \%$ & $-15 \%$ & $-14 \%$ & $-14 \%$ \\
\hline
\end{tabular}

heating system, what effect this would have on the life cycle impact of the building. The lower temperature is modelled as a night setback in this study. The modelling in this scenario hence considers a different control system for the heating system in order to differentiate the indoor air temperature between day zone and night zone of the house. The additional technical components consist of room thermostats, manifold, circulation pump, heat distribution pipes and an electricity cable to connect the room thermostats with the boiler. The new control system leads to a reduction in operational heating energy as the daily average indoor air temperature is lowered. To estimate the reduction, the same approach is used as for the scenario on increased wall insulation. Firstly, the energy savings for heating are calculated via dynamic energy simulations (Tables 8 and 9) by simulating both the baseline scenario and the scenario night setback setpoint temperature. The percentage reduction obtained is then multiplied with the heating energy of the baseline scenario based on statistical national data. The results from the dynamic energy simulations are summarized in Table 8 for the single family houses and in Table S7 (ESM) for the multifamily houses. The multiplication of the percentage reduction with the baseline scenario using the national statistical data is summarized in Table 9 and Table S8 (ESM).

For the production stage, the additional technical components as mentioned previously were modeled in the life cycle stage Production of additional materials needed for the ecoinnovation measure. It is assumed that in each bedroom, a room thermostat is placed, which results in three room thermostats per dwelling for the SFH and two room thermostats per dwelling for the MFH. The Ecoinvent LCI datasets listed in Table S9 (ESM) have been used for the modelling of these components. Table S10 summarizes the amounts of each of these components per dwelling.

The construction stage is modelled similarly as in the baseline scenario, i.e. assuming that $4 \%$ of the materials become construction waste and assuming the same transport scenario as for the other technical systems. No additional energy use is assumed for the installation of the additional components.

For the use phase-maintenance, it is assumed that $50 \%$ of the additional technical components are replaced every 25 years (in line with the other technical systems in the baseline scenario). Within a building life span of 100 years, it means that the components are replaced once. The LCI model takes into account the production, transport to construction phase and transport to EoL and EoL processes of the replaced components. No other maintenance activities are considered.

The end-of-life stage includes the dismantling process, transport to sorting plants, final disposal of waste materials and benefits from materials recycling and energy recovery (incineration). The end-of-life scenarios for each of the components are summarized in Table S11 (ESM).

\subsubsection{Scenario IV: combined scenario}

The combined scenario aims at assessing the potential effect of the combination of some of the measures tested in the previous scenarios. It assumes the combined implementation of three scenarios, namely night setback setpoint temperature HVAC, external wall insulation, and installation of a solar

Table 9 Single family houses: summary of the assumptions for the baseline scenario (Baldassarri et al. 2017) and night setback setpoint temperature scenario

\begin{tabular}{|c|c|c|c|c|c|c|c|c|c|c|c|c|}
\hline & \multicolumn{12}{|c|}{ Heating energy consumption $\left(\mathrm{kWh} / \mathrm{m}^{2}\right.$ year) } \\
\hline & \multicolumn{4}{|c|}{$\begin{array}{l}\text { Single family house zone } \\
\text { Warm zone }\end{array}$} & \multicolumn{4}{|c|}{$\begin{array}{l}\text { Single-family house } \\
\text { Moderate zone }\end{array}$} & \multicolumn{4}{|c|}{$\begin{array}{l}\text { Single-family house } \\
\text { Cold zone }\end{array}$} \\
\hline & $<1945$ & $\begin{array}{l}1945- \\
1969\end{array}$ & $\begin{array}{l}1970- \\
1989\end{array}$ & $\begin{array}{l}1990- \\
2010\end{array}$ & $<1945$ & $\begin{array}{l}1945- \\
1969\end{array}$ & $\begin{array}{l}1970- \\
1989\end{array}$ & $\begin{array}{l}1990- \\
2010\end{array}$ & $<1945$ & $\begin{array}{l}1945- \\
1969\end{array}$ & $\begin{array}{l}1970- \\
1989\end{array}$ & $\begin{array}{l}1990- \\
2010\end{array}$ \\
\hline Baseline scenario & 108 & 102 & 76 & 62 & 220 & 184 & 151 & 100 & 190 & 175 & 150 & 115 \\
\hline $\begin{array}{l}\text { Scenario night setback } \\
\text { temperature }\end{array}$ & 69 & 65 & 46 & 40 & 176 & 148 & 120 & 79 & 162 & 150 & 128 & 99 \\
\hline
\end{tabular}


Table 10 Characterized results, BoP housing energy-related scenarios (yearly impact EU citizen)

\begin{tabular}{|c|c|c|c|c|c|c|}
\hline Impact category & Unit & $\begin{array}{l}\text { Baseline } \\
\text { scenario }\end{array}$ & $\begin{array}{l}\text { Scenario wall } \\
\text { insulation (I) }\end{array}$ & $\begin{array}{l}\text { Scenario thermal } \\
\text { solar system (II) }\end{array}$ & $\begin{array}{l}\text { Scenario night } \\
\text { setback temperature (III) }\end{array}$ & $\begin{array}{l}\text { Combined } \\
\text { scenario (IV) }\end{array}$ \\
\hline Climate change & $\mathrm{kg} \mathrm{CO}_{2}$ eq & $2.62 \mathrm{E}+03$ & $2.33 \mathrm{E}+03$ & $2.56 \mathrm{E}+03$ & $2.36 \mathrm{E}+03$ & $2.08 \mathrm{E}+03$ \\
\hline Ozone depletion & $\mathrm{kg}$ CFC-11 eq & $3.33 \mathrm{E}-04$ & $2.93 \mathrm{E}-04$ & $3.24 \mathrm{E}-04$ & $2.98 \mathrm{E}-04$ & $2.60 \mathrm{E}-04$ \\
\hline Human toxicity, non-cancer effects & CTUh & $2.70 \mathrm{E}-04$ & $2.39 \mathrm{E}-04$ & $2.68 \mathrm{E}-04$ & $2.43 \mathrm{E}-04$ & $2.17 \mathrm{E}-04$ \\
\hline Human toxicity, cancer effects & CTUh & $3.48 \mathrm{E}-05$ & $3.29 \mathrm{E}-05$ & $3.51 \mathrm{E}-05$ & $3.31 \mathrm{E}-05$ & $3.20 \mathrm{E}-05$ \\
\hline Particulate matter & $\mathrm{kg} \mathrm{PM}_{2.5} \mathrm{eq}$ & $2.90 \mathrm{E}+00$ & $2.48 \mathrm{E}+00$ & $2.85 \mathrm{E}+00$ & $2.52 \mathrm{E}+00$ & $2.13 \mathrm{E}+00$ \\
\hline Ionizing radiation - human health & $\mathrm{kBq}^{235} \mathrm{eq}$ & $2.05 \mathrm{E}+02$ & $1.92 \mathrm{E}+02$ & $2.01 \mathrm{E}+02$ & $1.93 \mathrm{E}+02$ & $1.78 \mathrm{E}+02$ \\
\hline Photochemical ozone formation & $\mathrm{kg}$ NMVOC eq & $6.11 \mathrm{E}+00$ & $5.46 \mathrm{E}+00$ & $6.00 \mathrm{E}+00$ & $5.53 \mathrm{E}+00$ & $4.93 \mathrm{E}+00$ \\
\hline Acidification & molc $\mathrm{H}^{+}$eq & $1.34 \mathrm{E}+01$ & $1.21 \mathrm{E}+01$ & $1.32 \mathrm{E}+01$ & $1.23 \mathrm{E}+01$ & $1.10 \mathrm{E}+01$ \\
\hline Terrestrial eutrophication & molc $\mathrm{N}$ eq & $1.84 \mathrm{E}+01$ & $1.68 \mathrm{E}+01$ & $1.81 \mathrm{E}+01$ & $1.69 \mathrm{E}+01$ & $1.53 \mathrm{E}+01$ \\
\hline Freshwater eutrophication & $\mathrm{kg} P$ eq & $1.48 \mathrm{E}-01$ & $1.39 \mathrm{E}-01$ & $1.48 \mathrm{E}-01$ & $1.41 \mathrm{E}-01$ & $1.34 \mathrm{E}-01$ \\
\hline Marine eutrophication & $\mathrm{kg} \mathrm{N} \mathrm{eq}$ & $1.68 \mathrm{E}+00$ & $1.52 \mathrm{E}+00$ & $1.65 \mathrm{E}+00$ & $1.54 \mathrm{E}+00$ & $1.39 \mathrm{E}+00$ \\
\hline Freshwater ecotoxicity & CTUe & $1.14 \mathrm{E}+03$ & $1.04 \mathrm{E}+03$ & $1.13 \mathrm{E}+03$ & $1.05 \mathrm{E}+03$ & $9.61 \mathrm{E}+02$ \\
\hline Land use & $\mathrm{kg} \mathrm{C}$ deficit & $4.84 \mathrm{E}+03$ & $4.21 \mathrm{E}+03$ & $4.74 \mathrm{E}+03$ & $4.27 \mathrm{E}+03$ & $3.66 \mathrm{E}+03$ \\
\hline Water resource depletion & $\mathrm{m}^{3}$ water eq & $1.51 \mathrm{E}+02$ & $1.43 \mathrm{E}+02$ & $1.47 \mathrm{E}+02$ & $1.44 \mathrm{E}+02$ & $1.35 \mathrm{E}+02$ \\
\hline Mineral and fossil resource depletion & $\mathrm{kg} \mathrm{Sb}$ eq & $1.18 \mathrm{E}-01$ & $1.13 \mathrm{E}-01$ & $1.18 \mathrm{E}-01$ & $1.16 \mathrm{E}-01$ & $1.13 \mathrm{E}-01$ \\
\hline
\end{tabular}

collector. The three measures chosen for the combined scenario were selected because they can be jointly implemented on the same building (SFH or MFH). Interference of the measures was expected in terms of energy reduction obtained, and hence, the aim was to see if there were any trade-offs when implementing these measures jointly.

The modelling of the combined scenario is based on the same assumptions used for the modelling of the three separate scenarios. Therefore, the LCI of the combined scenario for what concerns the additional materials used (and related EoL) is simply the combination of the LCIs of the three scenarios modelled individually.

The only parameter that is specific for the combined scenario is the expected reduction in energy use and the change in the ratio of energy sources (in the case of DHW, due to the contribution of the solar collector, as it is in scenario II). To calculate the expected energy reduction, a new dynamic energy simulation has been run, similarly to the ones already developed for the individual scenarios.

\subsection{Life cycle impact assessment}

The potential environmental impacts have been calculated using the ILCD v.1.08 impact assessment method (ILCD 2011) (ECJRC 2011), which entails 15 impact categories. Long-term emissions were excluded, in line with the assessment of the baseline scenario. Given the importance of the characterisation of the resources when studying building, a sensitivity analysis has been carried out using CML-IA method v. 4.8. This method applies the abiotic depletion (ADP) concept, similarly to the version recommended in the ILCD method, but considering the contribution of energy carriers and mineral and metal
Fig. 3 Characterized results, BoP housing impact reduction percentage of eco-innovation scenarios compared to the baseline scenario (yearly impact EU citizen)

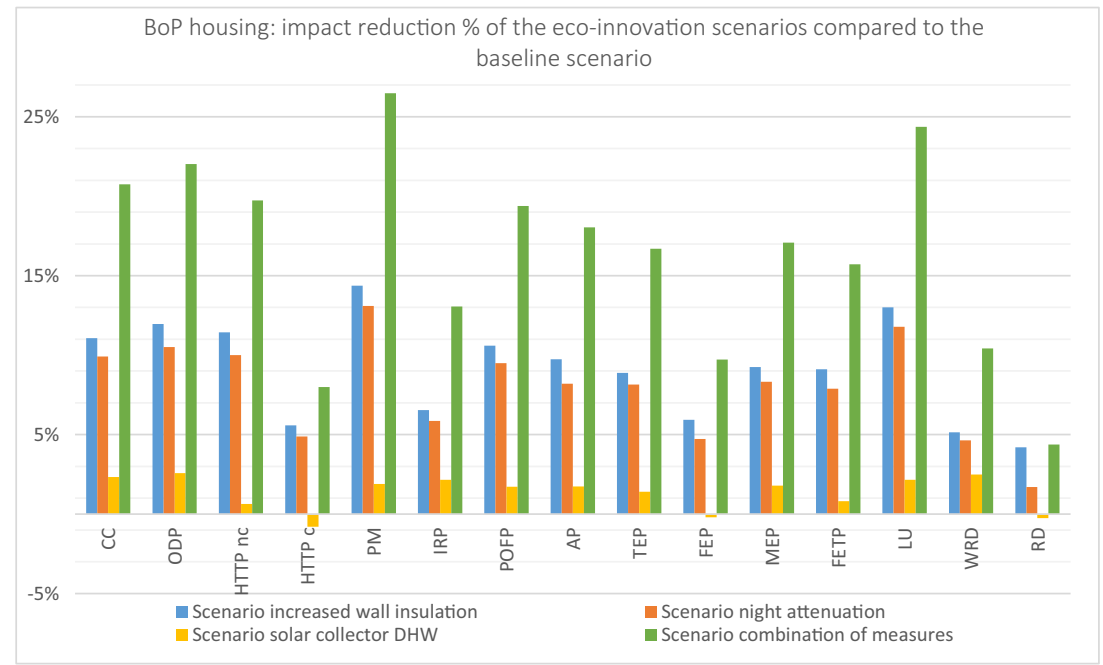


Table 11 Characterized results for resource depletion for fossil and metals/minerals, BoP housing energy-related scenarios (yearly impact EU citizen)

\begin{tabular}{|c|c|c|c|c|c|c|}
\hline Impact category & Unit & $\begin{array}{l}\text { Baseline } \\
\text { scenario }\end{array}$ & $\begin{array}{l}\text { Scenario wall } \\
\text { insulation }\end{array}$ & $\begin{array}{l}\text { Scenario thermal } \\
\text { solar system }\end{array}$ & $\begin{array}{l}\text { Scenario night setback } \\
\text { temperature }\end{array}$ & $\begin{array}{l}\text { Combined } \\
\text { scenario }\end{array}$ \\
\hline Abiotic depletion potential一fossil & MJ & $4.84 \mathrm{E}+04$ & $4.35 \mathrm{E}+04$ & $4.71 \mathrm{E}+04$ & $4.40 \mathrm{E}+04$ & $3.88 \mathrm{E}+04$ \\
\hline $\begin{array}{l}\text { Abiotic depletion potential- } \\
\text { minerals/metals (ultimate reserve) }\end{array}$ & $\begin{array}{c}\mathrm{kg} \mathrm{Sb} \\
\mathrm{eq}\end{array}$ & $5.13 \mathrm{E}-03$ & $4.95 \mathrm{E}-03$ & $5.29 \mathrm{E}-03$ & $5.01 \mathrm{E}-03$ & $4.98 \mathrm{E}-03$ \\
\hline
\end{tabular}

resources separately. In addition, it takes the crustal content as reference for the calculation of the ADP, instead of the reserve base, as it is in the version recommended in the ILCD method.

For each scenario, the results represent the potential benefits or impacts associated to household final consumption in the housing sector in Europe. The results in the subsequent section are presented as impact per person per year, adopting 2010 as reference year.

\section{Results and discussion}

In the subsequent sections, the results of the four scenarios are compared with the impact of the baseline scenario and discussed in more detail. The benefits as well as the additional burdens are emphasized.

Table 10 summarizes the characterized results for the baseline and eco-innovation scenarios for the whole BoP housing stock, expressed as impact per EU citizen. In the last column of the table, the results are shown for the three eco-innovation measures jointly. Figure 3 compares the impact of the various scenarios with the baseline scenario, for each of the impact categories.
In order to better understand the contribution of the two types of resources (metals/minerals versus fossil), the same inventory was characterized also using CML-IA method v. 4.8 as mentioned above. The results of this sensitivity analysis are presented in Table 11. The results show that the eco-innovation scenarios mainly lead to a reduction in fossil fuel depletion, ranging from a reduction of $3 \%$ for the thermal solar system to $20 \%$ for the combined scenario. The reduction in depletion of minerals/ metals is limited to a maximum of $4 \%$ (combined scenario).

The scenario "increased wall insulation" leads to a reduced impact in all impact categories and hence does not lead to any increase due to the additional insulation materials applied. The additional impacts related to these materials are all compensated by the energy reduction for heating. As illustrated in Fig. 4, the highest reductions (per EU citizen, per year) have been achieved (for most impact categories) for the SFH in the moderate climate and for the $\mathrm{MFH}$ in the warm climate and the smallest reductions for the $\mathrm{SFH}$ in the cold climate (taking into account the number of buildings in the BoP housing of each dwelling type). The analysis should not be limited to relative reductions as the latter can be misleading to set policy priorities. This is illustrated in Fig. 5 for global warming potential; the highest reduction (per person, year) is obtained for the increased
Fig. 4 Comparison of the LCIA of the scenario "increased wall insulation" with the baseline scenario: percentage reduction per person for each of the housing types (full stock assessed), for each of the impact categories

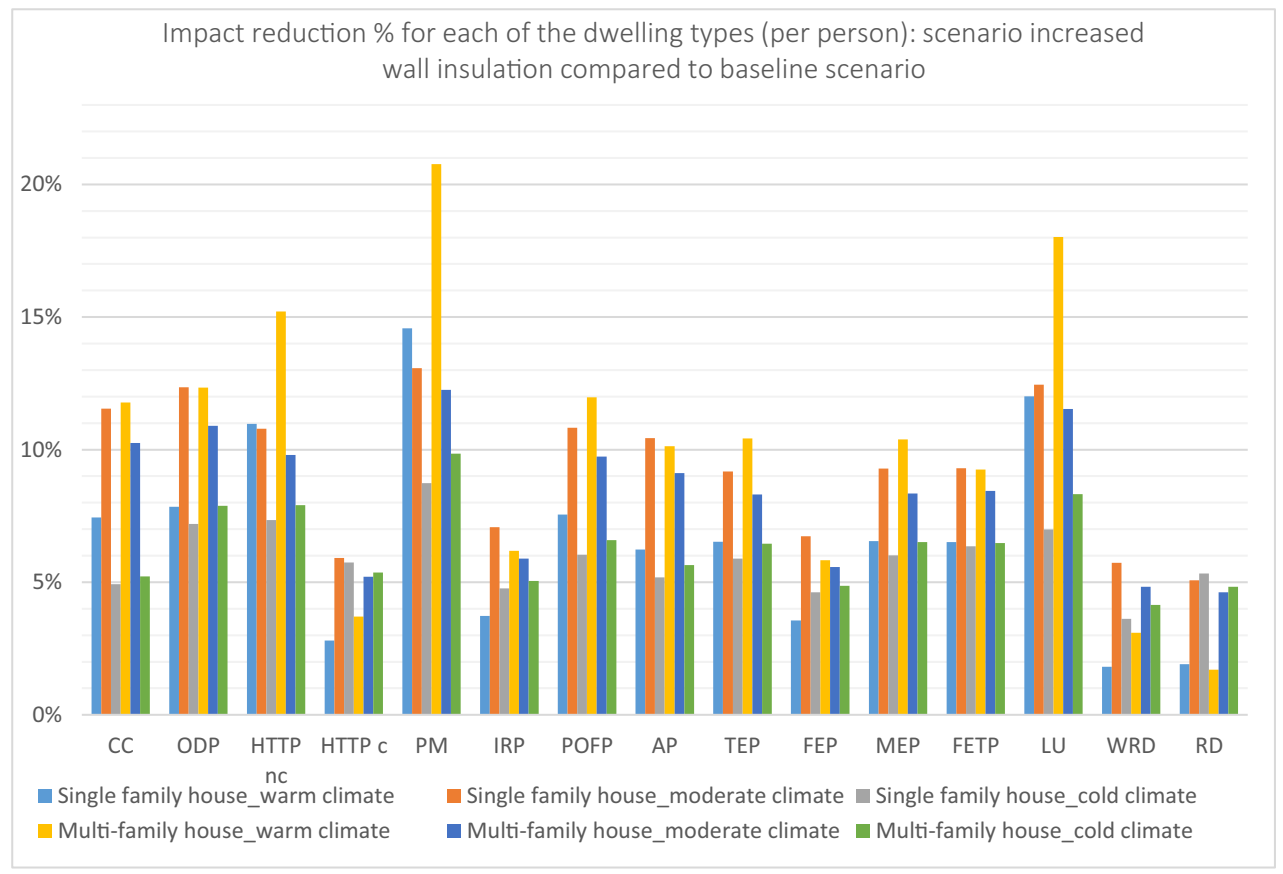


Fig. 5 Comparison of the reduction of climate change impacts (expressed as global warming potential - GWP) of the scenario "increased wall insulation" with the baseline scenario: reduction per person, year for each of the housing types (full stock assessed)

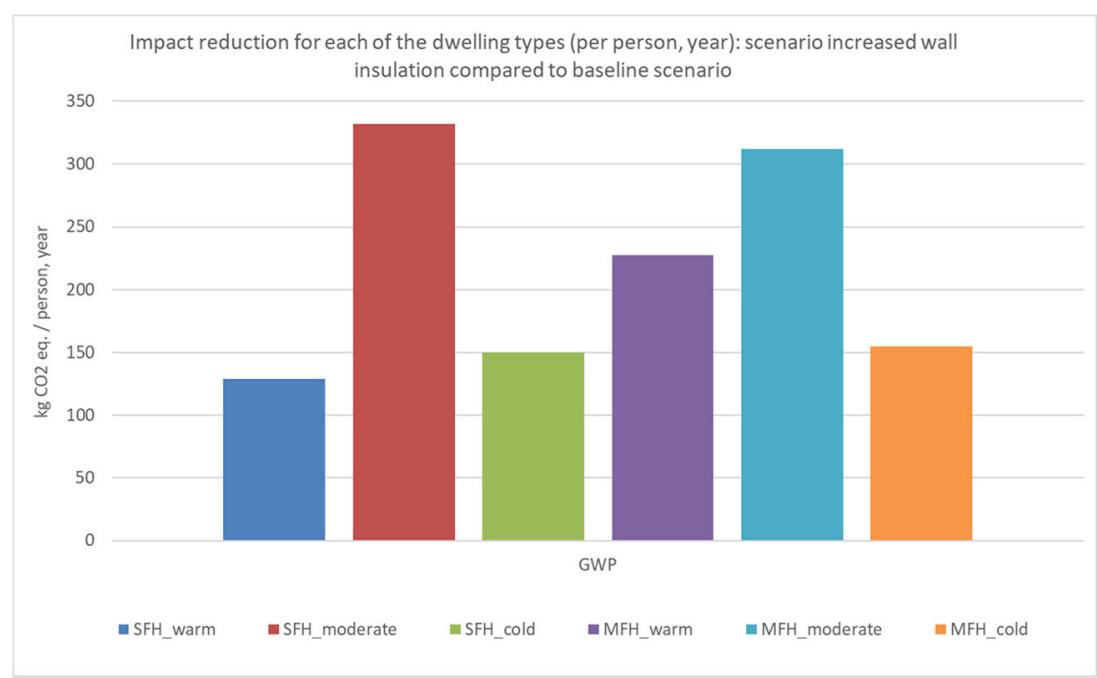

wall insulation in the SFH in the moderate climate and the lowest reduction in the $\mathrm{SFH}$ in the warm climate.

For an average EU housing, the reduction due to this ecoinnovation is highest for particulate matter (14\% reduction), followed by land use (12\%) and climate change, ozone depletion and human toxicity-cancer effects (all three $11 \%$ reduction). The lowest reduction is achieved for the impact category mineral, fossil and ren resource depletion (4\% reduction). As the increase in insulation level is quite limited for some of the dwelling types in this scenario, it is expected that higher benefits can be achieved by applying higher insulation levels than the ones assumed in this analysis. The scenario "thermal solar system" leads to a reduction of all impact categories except for human toxicity-cancer effects $(0.9 \%$ increase $)$ and mineral, fossil and ren resource depletion $(0.2 \%$ increase $)$. These are due to the components needed for the solar collector system. The impact decrease is rather small compared to the previous scenario, which can be explained by the lower relative contribution of DHW production compared to space heating. Per EU citizen, per year, the highest reductions have been achieved (for most impact categories) for the SFH in the warm climate and the smallest reductions for the MFH in the cold climate (taking into account the number of buildings in the BoP housing of each dwelling type). For an average EU housing, the reduction due to this eco-innovation measure is highest for ozone depletion $(2.5 \%)$, climate change $(2.4 \%)$, water resource depletion $(2.3 \%)$ and ionizing radiation $(2.1 \%)$.

The scenario "night setback setpoint temperature" leads to a reduced impact in all impact categories and hence does not lead to any increase due to the additional materials needed to
Fig. 6 Contribution of life cycle phases of the BoP housing for the baseline scenario and scenario increased wall insulation

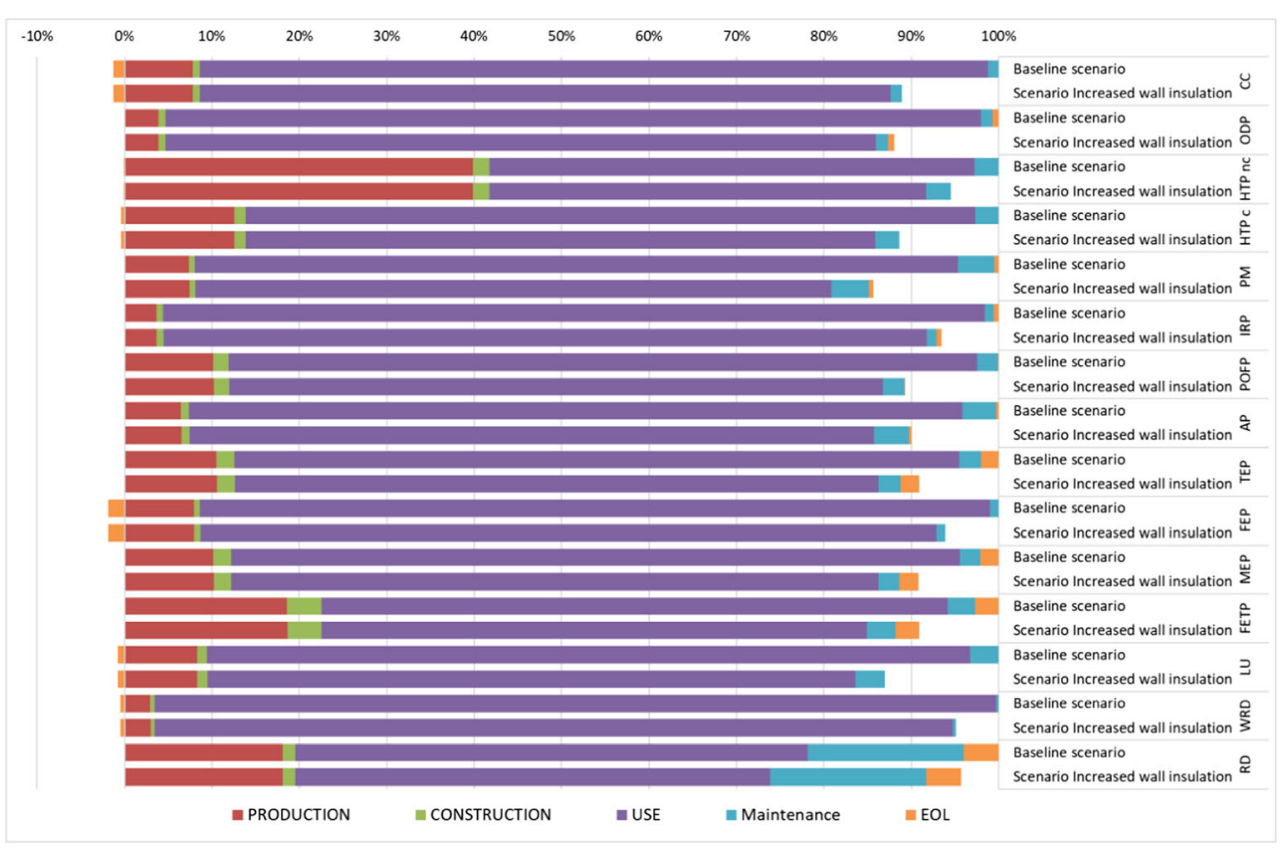


allow for the night attenuation. The additional impacts related to these additional materials are all compensated by the energy reduction for heating. Per EU citizen, per year, the highest reductions have been achieved for the SFH in the moderate climate and the smallest reductions for the MFH in the cold climate (taking into account the number of buildings in the BoP housing of each dwelling type). For an average EU housing, the reduction due to this eco-innovation is highest for particulate matter ( $13 \%$ reduction), followed by land use (12\%) and climate change, ozone depletion and human toxicity-cancer effects (all three $10 \%$ reduction). The lowest reduction is achieved for the impact category Mineral, fossil and ren resource depletion ( $1 \%$ reduction). This is similar as for the "increased wall insulation" scenario.

Although the impact of the use phase has reduced for each of the scenarios due to the eco-innovation measures, the use phase remains the most important life cycle stage in the impact of the BoP housing (illustrated in Fig. 6 for the scenario increased wall insulation). It is moreover noted that the impact reduction for most of the impact categories is relatively limited (less than 10\%). From this result, it can be concluded that a combination of several of these is needed to achieve a significant reduction in environmental impact of the overall BoP housing. This was confirmed by the results of the additional scenario combining the various measures, leading to a reduction of $15-20 \%$ for the majority of the impact categories, and of less than $10 \%$ for only two impact categories (human toxicity-cancer effects and abiotic resource depletion).

\section{Conclusions and outlook}

The results of the scenarios showed that the reduction in impact for each of the tested eco-innovation measures is relatively limited. It can hence be concluded that integrated measures are needed in order to achieve significant impact reductions of the EU building stock. This highlights that in the case of energy saving measures, a combination of actions would be needed to achieve significant improvements.

When interpreting the results of the scenarios, some limitations due to data sources and modelling choices have to be taken into account. The most important ones are the following:

- The use of archetypes is useful for analysing the effects of scenarios acting at the European level but implies also a certain degree of approximation at the building level, compared to the building-by-building approach. In fact, there is a trade-off between the data granularity of the model, which is higher at the small scale and lower at the large scale, and the relevance of the results obtained in support to policy decisions, which is of course higher when the model is built at a larger scale.
- With reference to the previous point, the uncertainty due to the use of average values instead of specific ones referred to real buildings may arise from the variability of service life of buildings, construction materials used, morphological features of the buildings, etc.

- Another limitation of the BoP baseline model used for this study is that the building stock is modelled in a static way and does not take into account stock dynamics over time. For instance, the effect of the European Energy Efficiency Directive is not captured in the basket of products housing, because its baseline year (2010) is the first year of implementation of the Directive. This aspect is reflected also in the results of the scenarios, which are modelled on the same reference buildings used in the baseline scenarios. It should also be pointed out that the construction of new buildings (that are adapted to the new regulation) suffered a setback due to the economic crisis of 2009, and existing buildings continue to be upgraded at a very low rate. It is estimated that the existing European building stock is currently being retrofitted at a rate of only approximately 1$3 \%$ of the total needed per year (Ascione et al. 2011).

- When using dynamic energy simulations applied to a stock of buildings modelled through archetypes, some simplifications are needed, in comparison of studies with dynamic simulations for specific buildings. In the present study, the dynamic simulations regarding the increase of envelope thermal resistance focused only on the $U$ value, while it is well known that also other parameters could influence the buildings energy performance (for instance, materials density and heat capacity). These properties would have been raised exponentially the cases to analyse, without leading to significant differences, as the study is limited to the winter conditions, when the envelope inertia plays a marginal role on the energy consumptions.

- The dynamic energy simulations in this study were limited to predict the heating demand. In further research, this could be broadened to include also cooling demand. This is especially important for warm climates, but even so for air-tight nearly zero energy buildings in moderate climates. As overheating risks in buildings are expected to become even more important due to climate change, it is recommended that this is further investigated in future research.

- Extending the analysis to the warm season, the effect of each action above described will be reduced in terms of energy saving respect to the total (whole year) energy consumption.

- Finally, as for all the LCA studies, the use of background databases (in this specific case, the Ecoinvent database 3.2 ) is a source of uncertainty because background data are not directly referred to the system under study. In the BoP housing, this aspect was partially addressed by adjusting the background datasets to the European average conditions as far as possible. 
The method applied in the study proved to have some innovative features that allowed for a detailed and reliable estimation of the impact of both the baseline and eco-innovation scenarios, especially for what concerns the use phase, i.e. the most relevant one. More specifically, a hybrid approach (combining a bottom-up and top-down approach) was used for the estimation of the energy reduction due to eco-innovation measures at macro-scale. In the present study, dynamic energy simulations are used to analyse the effect of eco-innovation measures at the micro-scale through the use of archetypes (bottom-up) and calibration of these based on a statistical analysis of the energy use by the EU housing stock (topdown), before upscaling to the European level. The assessment method allowed to take into account the major sources of variability existing within the building stock as well as occupants' behaviour by combining strengths of both topdown and bottom-up approaches and hence to support policy related to the building sector in an accurate way.

Firstly, the energy consumption in the use phase of archetype buildings is modelled with a top-down approach using data from the Intelligent Energy Europe Project ODYSSEE, which provides detailed data about energy consumption for space heating, space cooling, domestic hot water heating, lighting and use of appliances for each member state. This level of detail allowed for a detailed modelling of the effects of the scenarios on specific energy uses (e.g. thanks to the contribution of solar panels to domestic water heating). Moreover, the scenarios on energy efficiency were modelled with input data coming from dynamic energy simulation models, based on the specific features of the representative dwellings in the basket.

Secondly, the use of archetypes allowed for modelling the entire EU building stock. Compared to building-by-building approaches, the use of archetypes introduces some simplifications and uncertainties; however, the building-by-building approach is usually not applicable to large areas, because it is demanding for what concern data collection and modelling. The modelling of the entire building stock in EU (using archetypes of buildings) allows assessing the expected impact that measures taken at the building level can have at transnational scale, taking into account also the expected penetration rate of each measure (highlighting also regional differences) and the effect on different types of buildings.

Based on the use of the method proposed for the assessment of eco-innovation measures at the level of the European building stock, the method is seen as having a high potential for environmental evaluation of building related policy at any higher scale level, e.g. cities, regions or countries. In the current study, the upscaling of microscale measures assumed a $100 \%$ uptake of these in the EU building stock. This was an extreme case, which in reality is very unlikely to happen. However, the same approach could be used to investigate the needed potential uptake (of a combination of measures) to reach certain policy goals.

\section{Compliance with ethical standards}

Conflict of interest The authors declare that they have no conflict of interest.

Nomenclature BIM, Building information models; BPIE, Buildings Performance Institute Europe; CTU h, Comparative toxic unit—human health; CTU e, Comparative toxic unit-ecosystem; EPBD, Energy Performance of Buildings Directive; FU, Functional unit; IEE, Intelligent Energy Europe funding scheme; ILCD, International Life Cycle Data system; LCA, Life cycle assessment; LCI, Life cycle inventory; LCIA, Life cycle impact assessment; MFA, Material flow analysis; MFH, Multi family houses; NMVOC, Non-methane volatile organic chemicals; SFH, Single family houses; U, Transmittance

Impact categories AP, Acidification; CC, Climate change; FEP, Freshwater eutrophication; FETP, Freshwater ecotoxicity; HTP nc, Human toxicity, non-cancer effects; HTP c, Human toxicity, cancer effects; IRP, Ionizing radiation human health; LU, Land use; MEP, Marine eutrophication; ODP, Ozone depletion; PM, Particulate matter; POFP, Photochemical ozone formation; RD, Mineral and fossil resource depletion; TEP, Terrestrial eutrophication; WRD, Water resource depletion

Open Access This article is distributed under the terms of the Creative Commons Attribution 4.0 International License (http:// creativecommons.org/licenses/by/4.0/), which permits unrestricted use, distribution, and reproduction in any medium, provided you give appropriate credit to the original author(s) and the source, provide a link to the Creative Commons license, and indicate if changes were made.

Publisher's Note Springer Nature remains neutral with regard to jurisdictional claims in published maps and institutional affiliations.

\section{References}

Ajayi SO, Oyedele LO, Ceranic B, Gallanagh M, Kadiri KO (2015) Life cycle environmental performance of material specification: a BIMenhanced comparative assessment. Int J Sustain Build Technol Urban Dev 6(1):14-24

Allacker K, De Troyer F (2012) Optimisation of the environmental and financial cost of two dwellings in Belgium. Int J Sustain Dev Plan 7(2):186-208

ANSI/ASHRAE/IES Standard 90.1-2016 (2016) Energy standard for buildings except low-rise residential buildings

Asadi E, da Silva MG, Antunes CH, Dias L (2012) Multi-objective optimization for building retrofit strategies: a model and an application. Energ Build 44:81-87

Ascione F, de Rossi F, Vanoli GP (2011) Energy retrofit of historical buildings: theoretical and experimental investigations for the modelling of reliable performance scenarios. Energ Build 43(8):1925-1936

Asdrubali F, Baldassarri C, Fthenakis V (2013) Life cycle analysis in the construction sector: guiding the optimization of conventional Italian buildings. Energ Build 64:73-89

Azari R, Garshasbi S, Amini P, Rashed-Ali H, Mohammadi Y (2016) Multi-objective optimization of building envelope design for life cycle environmental performance. Energ Build $126: 524-534$ 
Baldassarri C, Allacker K, Reale F, Castellani V, Sala S (2017) Consumer Footprint. Basket of products indicator on housing, EUR 28765 EN, Publications Office of the European Union, Luxembourg

Ballarini I, Corgnati SP, Corrado V, (2014) Use of reference buildings to assess the energy saving potentials of the residential building stock: The experience of TABULA project. Energy Policy 68:273-284

Beccali G, Cellura M, Fontana M, Longo S, Mistretta M (2013) Energy retrofit of a single-family house: life cycle net energy saving and environmental benefits. Renew Sust Energ Rev 27:283-293

Bettgenhäuser K (2013) Integrated assessment modelling for the German building sector-a technical, economical and ecological analysis, pp 1-17

Birgisdottir H, Moncaster A, Wiberg AH, Chae C, Yokoyama K, Balouktsi M, Seo S, Oka T, Lützkendorf T, Malmqvist T (2017) IEA EBC annex 57 evaluation of embodied energy and $\mathrm{CO}_{2 \mathrm{eq}}$ for building construction. Energ Build 154:72-80

Biswas K, Shrestha SS, Bhandari MS, Desjarlais AO (2016) Insulation materials for commercial buildings in North America: an assessment of lifetime energy and environmental impacts. Energ Build 112:256-269

Boermans T, Bettgenhäuser K, Offermann M, Schimschar S (2012) Renovation tracks for Europe up to 2050, 2012. Report Ecofys by order of: EURIMA

Bortolin A, Bison P, Cadelano G, Ferrarini G, Fortuna S (2015) Measurement of thermophysical properties coupled with LCA assessment for the optimization of a historical building retrofit. IOP Publishing Ltd. Journal of Physics: Conference Series, Volume 655, conference 1

BPIE (2017) Buildings Performance Institute Europe, Data Hub. Available at: http://bpie.eu/focus-areas/buildings-data-and-tools/. Accessed Oct 2017

Brown NWO, Malmqvist T, Bai W, Molinari M (2013) Sustainability assessment of renovation packages for increased energy efficiency for multi-family buildings in Sweden. Build Environ 61:140-148

Cabeza LF, Rincón L, Vilariño V, Pérez G, Castell A (2013) Life cycle assessment (LCA) and life cycle energy analysis (LCEA) of buildings and the building sector: a review. Renew Sust Energ Rev 29:394-416

Caputo P, Costa G, Ferrari S (2013) A supporting method for defining energy strategies in the building sector at urban scale. Energy Policy 55:261-270

Cellura M, Guarino F, Longo S, Mistretta M (2017) Modelling the energy and environmental life cycle of buildings: a co-simulation approach. Renew Sust Energ Rev 80:733-742

Directive 2010/31/EU (2010) Directive of the European Parliament and of the Council of 19 May 2010 on the energy performance of buildings

Directive 2012/27/EU (2012) Directive of the European Parliament and of the Council of 25 October 2012 on energy efficiency, amending Directives 2009/125/EC and 2010/30/EU and repealing

Dol K, Haffner M (2010) Housing statistics in the European Union 2010. Delft University of Technology. www.bmdw.gv.at/ Wirtschaftspolitik/Wohnungspolitik/Documents/housing_statistics_ in the european union 2010.pdf. Accessed July 2018

European Commission (EC) (2012a) Commission Delegated Regulation (EU) No. 244/2012 of 16 January 2012 Supplementing Directive 2010/31/EU of the European Parliament and of the council on the energy performance of buildings by establishing a comparative methodology framework for calculating cost-optimal levels of minimum energy performance requirements for buildings and building elements. Official Journal of the European U, 21 March, 2012

EC (2012b) Guidelines accompanying Commission Delegated Regulation (EU) No. 244/2012 of 16 January 2012 supplementing Directive 2010/31/EU of the European Parliament and of the council on the energy performance of buildings by establishing a comparative methodology framework for calculating cost-optimal levels of minimum energy performance requirements for buildings and building elements Official Journal of the European Union, 19 April 2012

EC (2014) Communication on resource efficiency opportunities in the building sector by the European Commission. COM (2014) 445
EC-JRC (2008) Environmental improvement potential of residential buildings (IMPRO-buildings). Publications Office of the European Union, Luxembourg EUR 23493 EN. ISBN 978-92-79-09767-6

EC-JRC (2011) Joint Research Centre ILCD handbook-recommendations based on existing environmental impact assessment models and factors for life cycle assessment in European context. Publications Office of the European Union, Luxembourg EUR24571EN. ISBN 978-92-7917451-3. http://eplca.jrc.ec.europa.eu/

ENTRANZE (2014) Policies to ENforce the TRAnsition to Nearly Zero Energy buildings in the EU-27. http://www.entranze.eu . Accessed August 2018

EPISCOPE Project (2013-2016) IEE Project. Energy performance indicators for building stocks. http://episcope.eu

Famuyibo AA, Duffy A, Strachan P (2013) Achieving a holistic view of the life cycle performance of existing dwellings. Build Environ 70:90-101

Gustafsson M, Dipasquale C, Poppi S, Bellini A, Fedrizzi R, Bales C, Ochs F, Sié M, Holmberg S (2017) Economic and environmental analysis of energy renovation packages for European office buildings. Energ Build 148:155-165

Heeren N, Jakob M, Martius G, Gross N, Wallbaum H (2013) A component based bottom-up building stock model for comprehensive environmental impact assessment and target control. Renew Sust Energ Rev 20(C):45-56

Inyim P, Zhu Y (2013) A framework for integrated analysis of building designs using a life-cycle assessment and energy simulation. ICCREM 2013: Construction and Operation in the Context of Sustainability

Jrade A, Jalaei F (2012) Integrating building information modelling and life cycle assessment tools to design sustainable Building In: Proceedings of the CIB W78 2012: 29th International Conference. Beirut, Lebanon. 17-19 October: 173-82

Kavgic M, Mavrogianni A, Mumovic D, Summerfield A, Stevanovic Z, Djurovic-Petrovic M (2010) A review of bottom-up building stock models for energy consumption in the residential sector. Build Environ 45(7):1683-1697

Lavagna M, Giorgi S, Dalla Valle A (2016) Abitare in Europa. Analisi dei dati statistici, definizione di modelli rappresentativi e valutazione ambientale LCA del patrimonio residenziale europeo (in Italian). Maggioli Editore, Santarcangelo di Romagna (RN), Italy. ISBN: 978-88-916-1526-8

Lavagna M, Baldassari C, Campioli A, Giorgi S, Dalla Valle A, Castellani V, Sala S (2018) Benchmarks for environmental impact of housing in Europe: definition of archetypes and LCA of the residential building stock. Build Environ 145: 260-275

Loga T, Stein B, Diefenbach N (2016) TABULA building typologies in 20 European countries - making energy-related features of residential building stocks comparable. Energ Build 132:4-12

Lolli N, Mamo Fufa S, Inman M (2017) A parametric tool for the assessment of operational energy use, embodied energy and embodied material emissions in building. Energy Procedia 111:21-30

Lotteau M, Loubet P, Pousse M, Dufrasnes E, Sonnemann G (2015) Critical review of life cycle assessment (LCA) for the built environment at the neighborhood scale. Build Environ 93(2):165-178

Ma Z, Cooper P, Daly D, Ledo L (2012) Existing building retrofits: methodology and state-of-the-art. Energ Build 55:889-902

Mastrucci A, Marvuglia A, Leopold U, Benetto E (2017) Life cycle assessment of building stocks from urban to transnational scales: a review. Renew Sust Energ Rev 74:316-332

Mata É, Sasic Kalagasidis A, Johnsson F (2013) Energy usage and technical potential for energy saving measures in the Swedish residential building stock. Energy Policy 55:404-414

McKenna R, Merkel E, Fehrenbach D, Mehne S, Fichtner W (2013) Energy efficiency in the German residential sector: a bottom-up building-stock-model-based analysis in the context of energypolitical targets. Build Environ 62:77-88 
Meijer F, Itard L (2008) Towards a sustainable Northern European housing stock: figures, facts and future. IOS Press, 2008. ISBN: 978-158603-977-6

Nemry F, Uihlein A, Colodel CM, Wetzel C, Braune A, Wittstock B, Hasan I, Kreissig J, Gallon N, Niemeier S, Frech Y (2010) Options to reduce the environmental impacts of residential buildings in the European Union - potential and costs. Energ Build 42(7):976-984

Nichols BG, Kockelman KM (2014) Life-cycle energy implications of different residential settings: recognizing buildings, travel, and public infrastructure. Energy Policy 68:232-242

ODYSSEE (2016) IEE Project. Energy efficiency indicators in Europe. Available at: http://www.odyssee-mure.eu/ . Accessed August 2018

Onat NC, Egilmez G, Tatari O (2014) Towards greening the U.S. residential building stock: a system dynamics approach. Build Environ 78:68-80

Ostermeyer Y, Wallbaum H, Reuter F (2013) Multidimensional Pareto optimization as an approach for site-specific building refurbishment solutions applicable for life cycle sustainability assessment. Int J Life Cycle Assess 18:1762-1779

Papadopoulos AM (2005) State of the art in thermal insulation materials and aims for future developments. Energ Build 37(1):77-86

Pauliuk S, Sjöstrand K, Müller DB (2013) Transforming the Norwegian dwelling stock to reach the 2 degrees Celsius climate target. J Ind Ecol 17(4):542-554

Pedersen F, Hansen K, Wittchen KB, Grau KE, Johnsen K (2008) Combining building thermal simulation methods and LCA methods. In: Proceedings of the NSB2008, 8th Symposium on Building Physics in the Nordic Countries. Copenhagen, Denmark, 16-18 June, pp 605-611

Petersen EH (1999) LCA tool for use in the building industry. Int J Low Energ Sust Build 1:1-11 ISSN: 1403-2147

Peuportier B, Thiers S, Guiavarch A (2013) Eco-design of buildings using thermal simulation and life cycle assessment. J Clean Prod 39:73-78

Pombo O, Allacker K, Rivela B, Neila J (2016) Sustainability assessment of energy saving measures: a multi-criteria approach for residential buildings retrofitting - a case study of the Spanish housing stock. Energ Build 116:384-394

Rodrigues C, Freire F (2014) Integrated life-cycle assessment and thermal dynamic simulation of alternative scenarios for the roof retrofit of a house. Build Environ 81:204-215

Roux C, Schalbart P, Assoumou E, Peuportier B (2016) Integrating climate change and energy mix scenarios in LCA of buildings and districts. Appl Energy 184:619-629

Sala S, Farioli F, Zamagni A (2013) Progress in sustainability science: lessons learnt from current methodologies for sustainability assessment (part I). Int J Life Cycle Assess 18:1653-1672

Sandberg NH, Brattebø H (2012) Analysis of energy and carbon flows in the future Norwegian dwelling stock. Build Res Inf 40(2):123-139
Sandberg NH, Bergsdal H, Brattebø H (2011) Historical energy analysis of the Norwegian dwelling stock. Build Res Inf 39(1):1-15

Saner D, Heeren N, Jäggi B, Waraich RA, Hellweg S (2013) Housing and mobility demands of individual households and their life cycle assessment. Environ Sci Technol 47(11):5988-5997

Sartori I, Wachenfeldt BJ, Hestnes AG (2009) Energy demand in the Norwegian building stock: scenarios on potential reduction. Energy Policy 37(5):1614-1627

Scheuer C, Keoleian GA, Reppe P (2003) Life cycle energy and environmental performance of a new university building: modeling challenges and design implications. Energ Build 35:1049-1064

Seo S et al (2016) Evaluation of embodied energy and CO2eq for building construction (Annex 57). www.annex57.org/wp/wp-content/ uploads/2017/05/Summary-Report.pdf

Silva PCP, Almeida M, Bragança L, Mesquita V (2013) Development of prefabricated retrofit module towards nearly zero energy buildings. Energ Build 56:115-125

Stazi F, Tomassoni E, Di Perna C (2017) Super-insulated wooden envelopes in Mediterranean climate: summer overheating, thermal comfort optimization, environmental impact on an Italian case study. Energ Build 138:716-732

Theodoridou I, Papadopoulos AM, Hegger M (2011) A typological classification of the Greek residential building stock. Energ Build 43(10):2779-2787

Thiers S, Peuportier B (2012) Energy and environmental assessment of two high energy performance residential buildings. Build Environ 51:276-284

Vásquez F, Løvik AN, Sandberg NH, Müller DB (2016) Dynamic typecohort-time approach for the analysis of energy reductions strategies in the building stock. Energ Build 111:37-55

Vilches A, Garcia-Martinez A, Sanchez-Montañes B (2017) Life cycle assessment (LCA) of building refurbishment: a literature review. Energ Build 135:286-301

Vrijders J, Herinckx S, Wastiels L, Delem L (2012) One-stop-shopfrom demonstration projects towards volume market: innovations for one stop shop in sustainable renovation. Available at http:// www.one-stopshop.org/sites/default/files/Optimal-RenovationStrategies.pdf. Accessed July 2018

Wong JKW, Zhou J (2015) Enhancing environmental sustainability over building life cycles through green BIM: a review. Autom Constr 57: $156-165$

Yu X, Nongaillard A, Sekhari A, Bouras A (2016) An environmental burden shifting approach to re-evaluate the environmental impacts of products. In: Bouras a, Eynard B, Foufou S, Thoben KD (eds) Product lifecycle management in the era of Internet of things. PLM 2015. IFIP Advances in Information and Communication Technology, vol 467. Springer. https://doi.org/10.1007/978-3-319-33111-9_6 